Document downloaded from:

http://hdl.handle.net/10251/156028

This paper must be cited as:

Piqueras, P.; García Martínez, A.; Monsalve-Serrano, J.; Ruiz, MJ. (2019). Performance of a diesel oxidation catalyst under diesel-gasoline reactivity controlled compression ignition combustion conditions. Energy Conversion and Management. 196:18-31.

https://doi.org/10.1016/j.enconman.2019.05.111

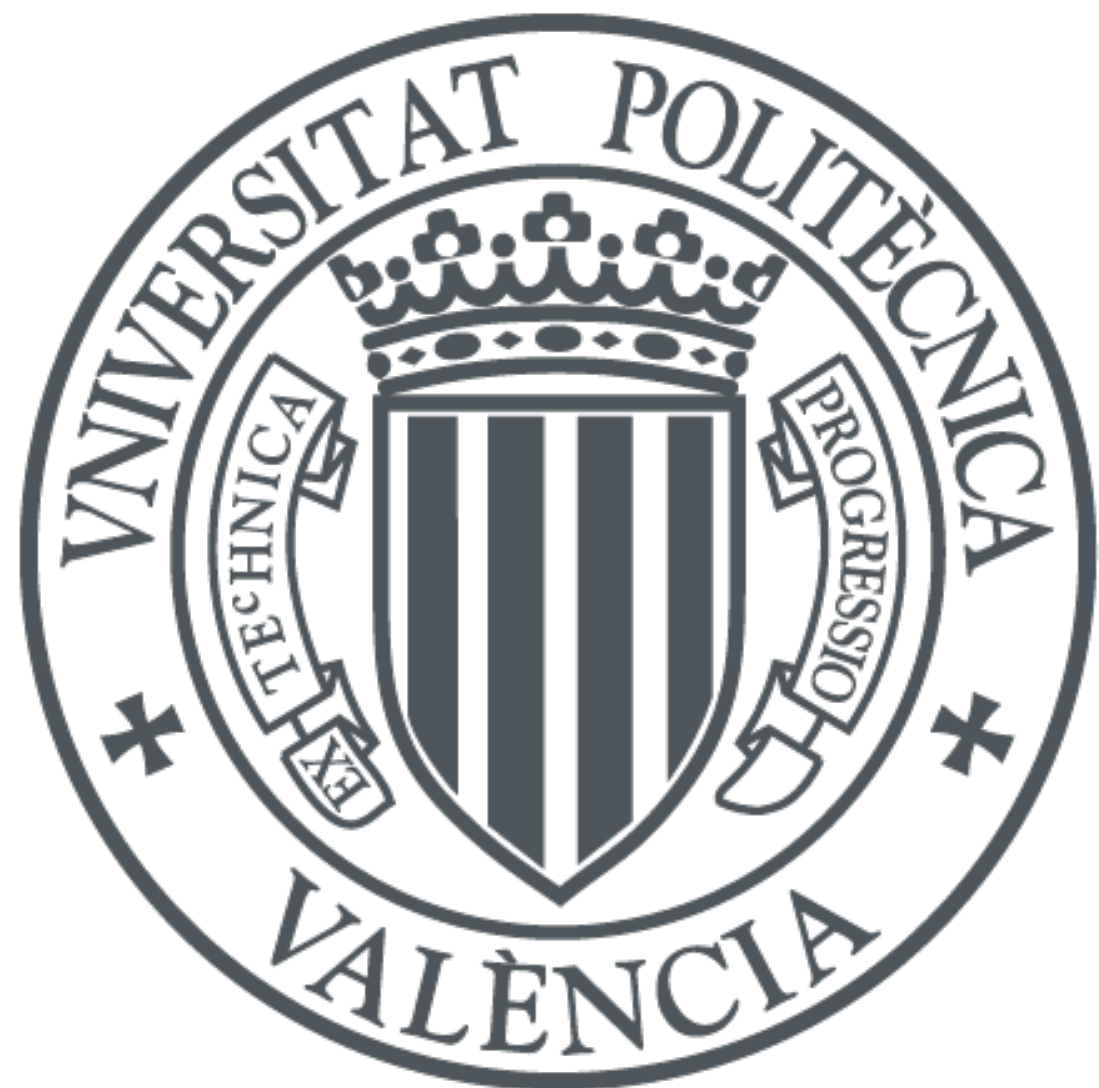

The final publication is available at

https://doi.org/10.1016/j.enconman.2019.05.111

Copyright Elsevier

Additional Information 


\title{
Performance of a diesel oxidation catalyst under diesel-gasoline reactivity controlled compression ignition combustion conditions
}

\author{
Pedro Piqueras*, Antonio García, Javier Monsalve-Serrano, María José Ruiz \\ CMT-Motores Térmicos, Universitat Politècnica de València, Camino de Vera s/n, 46022 Valencia, Spain. \\ Energy Conversion and Management 196 (2019) 18-31 \\ https://doi.org/10.1016/j.enconman.2019.05.111
}

\begin{abstract}
Reactivity controlled compression ignition is a promising combustion strategy due to the combination of excellent thermal efficiency with ultra-low nitrogen oxides and particulate matter raw emissions. However, very high levels of unburned hydrocarbons and carbon monoxide emissions are found. It limits the reactivity controlled compression ignition use at very low loads and presents an additional challenge for the diesel oxidation catalyst. The low exhaust temperature and high carbon monoxide and hydrocarbon concentration can penalise the catalyst conversion efficiency. The objective of this work is to evaluate the response of an automotive diesel oxidation catalyst when used for reactivity controlled compression ignition combustion combining experimental and modelling approaches. For this purpose, dedicated tests have been done using diesel-gasoline as fuel combination in a single-cylinder engine. This way, the catalyst conversion efficiency has been determined within a wide operating range covering hydrocarbon adsorption conditions and the pollutants abatement dependence on the mass flow and temperature. The experimental results in the full-size catalyst has been analysed by modelling. A lumped diesel oxidation catalyst model has been applied to extend the results to multi-cylinder engine conditions and to determine the light-off curves for both carbon monoxide and hydrocarbons. These tests evidence the penalty in light-off temperature due to high pollutants mass fraction, which promotes inhibition limitations to the reaction rate.
\end{abstract}

Keywords: Emissions, Aftertreatment, Diesel oxidation catalyst, Reactivity controlled compression ignition,

Dual-fuel combustion

\section{Introduction}

Compression ignition engines offer high efficiency with moderate engine-out emissions [1]. By this reason, this engine platform is widely used worldwide to propel light-duty and heavy-duty vehicles. As a counterpart, the massive use of this technology is contributing to aggravate the global-warming phenomenon and worsen the air quality in the cities. To minimise their impact on both the environment and human health, the emissions standards are continuously evolving to restrict the maximum emissions levels accepted during the homologation process of the vehicles [2].

${ }^{*}$ Corresponding author. Tel.: +34 963877650 , fax: +34963877659 .

Email address: pedpicab@mot.upv.es (Pedro Piqueras) 
From the different pollutant emissions generated during conventional diesel combustion (CDC), nitrogen oxides (NOx) and soot have been identified as the most harmful ones due to their noxious effects on the human health. To reduce the emissions of NOx and soot, the production diesel vehicles require having installed exhaust aftertreatment systems (ATS) able to deal with these emissions [3]. Due to the fine materials used for their production, the use of the ATS results in a noticeable increase of the final vehicle cost [4]. Moreover, the operation costs also increase due to the need of extra exhaust fluids, as per example diesel fuel for active DPF regenerations [5] or urea injection upwards the SCR [6]. Finally, the ATS increases the back-pressure at the exhaust manifold due to new elements in the exhaust line and the soot loading in the DPF [7], which reduces the expansion work of the piston and therefore increases the fuel consumption [8].

To minimise the ATS requirements, alternative combustion concepts are being investigated nowadays with the aim of achieving engine-out emissions levels near to those imposed by the current legislation [9]. Recent researches have demonstrated that the low temperature combustion (LTC) strategies are able to provide efficiency benefits versus CDC while reducing the engine-out NOx and soot emissions simultaneously [10]. This reduction is possible by operating with highly diluted fuel-air mixtures at the combustion chamber, which also leads to increase the fuel-air mixing time before the start of combustion [11]. On the other hand, the efficiency gain versus CDC comes from the combustion duration reduction and heat transfer minimisation [12].

The most recent literature in this field demonstrates that the dual-fuel concept so-called reactivity controlled compression ignition (RCCI) has the highest potential to increase the efficiency and reduce the emissions. This is mainly because RCCI can be applied in a wider range of operating conditions than other LTC concepts [13]. This ability is possible thanks to using two fuels of different reactivity, injected to the cylinder using separated injection systems [14]. The high reactivity fuel (HRF) is injected into the cylinder using a direct injector (DI), while the low reactivity fuel (LRF) is fumigated in the intake port [15]. Regarding the fuels proportion, it has been demonstrated that to achieve high efficiency and low emissions, the LRF must account for the major part of the total fuel injected, while the HRF is the responsible of triggering the combustion process [16]. In any case, the HRF injection strategy should be carefully studied to generate the necessary in-cylinder reactivity stratification that ensures a proper development of the combustion process [17]. Additionally, a proper reactivity gradient leads to a sequential autoignition [18], reducing the in-cylinder pressure rise rates (PRR) and enabling a proper operation in a greater load range.

The RCCI potential has been proved by many authors concluding that this combustion strategy can lead to engineout NOx levels below the limits proposed by the emissions regulations, together with ultra-low soot emissions [19]. Nonetheless, some challenges still limit its practical application. To avoid these challenges, the dual-mode concept is being extensively investigated in the recent years to look for the optimum balance between emissions [20] and engine efficiency [21]. While NOx and soot emissions with the dual-mode RCCI/CDC are very low, unburned hydrocarbons (HC) and carbon monoxide (CO) emissions levels are still orders of magnitude greater than with CDC [22]. Moreover, the major part of the $\mathrm{HC}$ and $\mathrm{CO}$ emissions are emitted during RCCI operation, when the exhaust temperature is low. Therefore the diesel oxidation catalyst (DOC) efficiency can be compromised due to chemical kinetics limitations 
[23]. The conversion efficiency might find to be also limited by bulk mass transfer [24], high CO and HC mass fraction [25] and HC adsorption capability during the warm-up phase [26]. Moreover, the gasoline to diesel ratio varies across the RCCI engine map. Therefore, the chemical composition of the unburned compounds, in particular the presence of high and low reactivity species [27], takes more importance. To deal with all these phenomena, modelling tools arise as a necessary complement to the experimental data analysis. The use of computational models must provide robustness, feasibility and cost effectiveness at the same time as deep understanding of the governing physical and chemical phenomena. Different approaches for monolithic flow-through devices have been proposed in the literature based on 1D solvers [28], low dimensional models based on the averaging of the governing equations [29], use of neural networks [30] or control-oriented concepts [31]. A lumped DOC model [32] is used in this work as a particular response to the need of flexible computational tools for exhaust aftertreatment systems. The heat transfer modelling is based on a lumped nodal approach that allows predicting the substrate temperature from the solution of the heat transfer equations in the monolith and the metal canning. This temperature governs the abatement of gaseous pollutants, which is explicitly determined solving the chemical species transport in the bulk gas and washcoat regions under quasi-steady flow assumption.

The objective of this work is to assess the response of a passenger car engine Euro 6 DOC when used under the boundary conditions of RCCI combustion. For this purpose, dedicated experimental tests have been carried out using diesel-gasoline as fuel combination in a single-cylinder engine where combustion conditions are controlled with high sensitivity. The test campaign has provided the $\mathrm{CO}$ and $\mathrm{HC}$ conversion efficiency within a wide operating range that accounts for hydrocarbon adsorption conditions and the pollutants abatement dependence on the mass flow and temperature. The experimental results have been reproduced by the lumped DOC model, which provides sensitivity to limiting conversion efficiency phenomena such as bulk mass transfer, chemical species inhibition and internal pore diffusion. Its use allows analysing in depth the experimental DOC performance as a previous step to discuss the DOC potential and limitations for $\mathrm{CO}$ and $\mathrm{HC}$ abatement under multi-cylinder RCCI operation in contrast to the baseline CDC combustion.

\section{Materials and methods}

In this section, the main characteristics of the experimental facility are firstly provided. Next, the test procedure carried out to determine the DOC performance is described in detail.

\subsection{Engine, test cell and fuels description}

The single-cylinder diesel engine used for the experiments is based on a serial production light-duty $1.9 \mathrm{~L}$ platform. The engine has four valves driven by dual overhead cams. The piston used is the serial one, with a re-entrant bowl that confers a geometric compression ratio of 17.1:1. The swirl ratio was fixed at 1.4, which is a representative value of that used in the stock engine configuration, using tangential and helical valves located in the intake port [33]. Table 1 summarises the more relevant characteristics of the engine. 
Table 1: Main characteristics of the engine.

\begin{tabular}{lc}
\hline \hline Engine type & 4 stroke, 4 valves, direct injection \\
Number of cylinders [-] & 1 \\
Displaced volume $\left[\mathrm{cm}^{3}\right]$ & 477 \\
Stroke [mm] & 90.4 \\
Bore [mm] & 82 \\
Piston bowl geometry [-] & Re-entrant \\
Compression ratio [-] & $17.1: 1$ \\
Rated power [kW] & $27.5 @ 4000 \mathrm{rpm}$ \\
Rated torque [Nm] & $80 @ 2000-2750 \mathrm{rpm}$ \\
\hline \hline
\end{tabular}

The fuel injection system was adapted to allow RCCI operation as shown in Figure 1. As sketched, the EN590 diesel fuel was injected into the cylinder by means of a centrally located solenoid direct injector (DI) coupled with a common-rail fuel injection system. The injection settings were managed using a DRIVVEN controller. The gasoline fuel was fumigated in the intake manifold using a port fuel injection (PFI) located $160 \mathrm{~mm}$ far from the intake valves, which was governed through a Genotec unit. The mass flow rate of both fuels was measured using dedicated AVL $733 \mathrm{~S}$ fuel balances. The main characteristics of the DI and PFI are depicted in Table 2 and the most relevant properties of the fuels used in this study are summarised in Table 3.

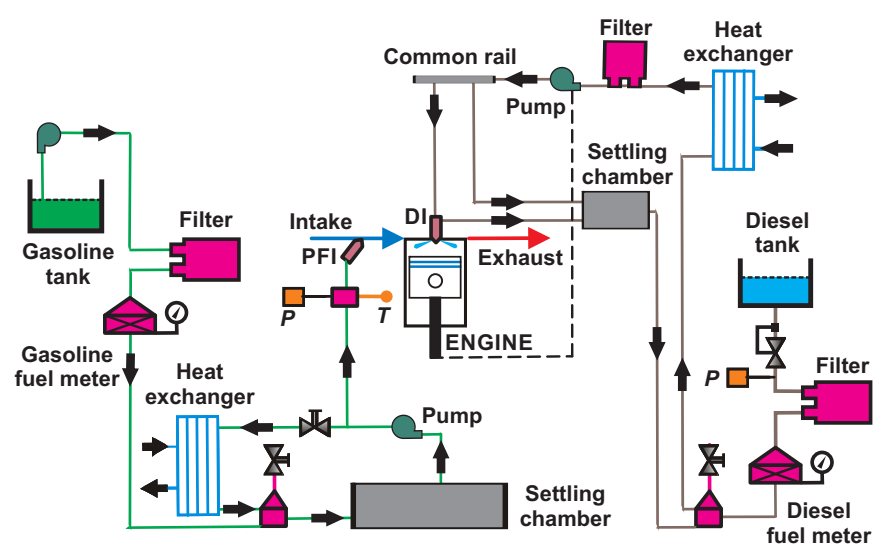

Figure 1: Scheme of the fuel injection systems.

The scheme of the test cell in which the engine has been operated is shown in Figure 2. An electric dynamometer is used for the engine speed and load control during the experiments. The air intake line is composed of a screw compressor, which feeds the engine with fresh air at a pressure up to $3 \mathrm{bar}$, a heat exchanger and an air dryer to modify the temperature and relative humidity of the air, airflow meter and a settling chamber sized to attenuate the intake pulsating flow. Moreover, pressure and temperature transducers are instrumented in this element with 
Table 2: Characteristics of the direct and port fuel injectors

\begin{tabular}{lc}
\multicolumn{1}{c}{ Direct injector } \\
\hline Actuation type [-] & Solenoid \\
Steady flow rate @ 100 bar $\left[\mathrm{cm}^{3} / \mathrm{min}\right]$ & 880 \\
Included spray angle [ $\left.{ }^{\circ}\right]$ & 148 \\
Number of holes [-] & 8 \\
Hole diameter [ $\mu \mathrm{m}]$ & 141 \\
Maximum injection pressure [bar] & 1600 \\
\hline \multicolumn{1}{c}{ Port fuel injector } & Saturated \\
\hline Injector style [-] & 980 \\
Steady flow rate @ 3 bar $\left[\mathrm{cm}^{3} / \mathrm{min}\right]$ & 30 \\
Included spray angle [ ${ }^{\circ}$ ] & single \\
Injection strategy [-] & 340 \\
Start of injection [CAD ATDC] & 5.5 \\
Maximum injection pressure [bar] & \\
\hline \hline
\end{tabular}

Table 3: Physical and chemical properties of the fuels.

\begin{tabular}{lcc}
\multicolumn{3}{c}{ Table 3: Physical and chemical properties of the fuels. } \\
\hline \hline & Diesel EN590 & Gasoline \\
Density $\left[\mathrm{kg} / \mathrm{m}^{3}\right]\left(\mathrm{T}=15^{\circ} \mathrm{C}\right)$ & 842 & 747 \\
Viscosity $\left[\mathrm{mm}^{2} / \mathrm{s}\right]\left(\mathrm{T}=40^{\circ} \mathrm{C}\right)$ & 2.929 & 0.545 \\
RON [-] & - & 97.6 \\
MON [-] & - & 89.7 \\
Ethanol content [\% vol.] & - & - \\
Cetane number [-] & 51 & - \\
Lower heating value $[\mathrm{MJ} / \mathrm{kg}]$ & 42.5 & 44.09 \\
\hline \hline
\end{tabular}


regulation purposes. The exhaust gas recirculated (EGR) is introduced in the intake line, downwards the settling chamber, through a dedicated line composed of a heat exchanger, a settling chamber and a regulation valve. The EGR temperature is monitored in several points along the line for its control. Finally, the pressure and temperature of the air-EGR mixture is measured in the intake manifold before entering to the cylinder.

The DOC is the first element of the exhaust line. As sketched in Figure 2, the pressure and temperature are measured at the inlet and outlet of the DOC, whose main geometrical parameters are listed in Table 4. A Euro 6 full-size passenger car DOC has been considered in this study.

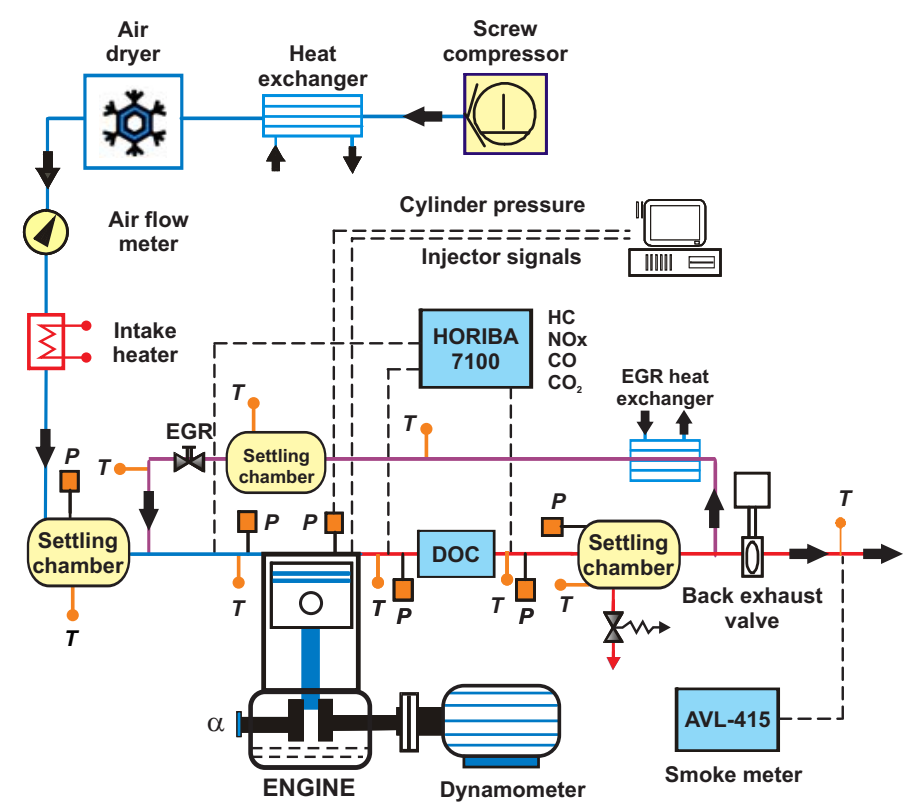

Figure 2: Scheme of the single-cylinder engine test cell.

\begin{tabular}{lc} 
Table 4: Main DOC geometric parameters. \\
\hline \hline Diameter [m] & 0.172 \\
Length [m] & 0.082 \\
Cell density [cpsi] & 400 \\
Channel width [mm] & 1.17 \\
Wall thickness [mm] & 0.101 \\
Catalytic area [m²] & 5.5 \\
Channel cross-section & Square \\
\hline \hline
\end{tabular}

A five-gas Horiba MEXA-7100 DEGR analyser was used to measure the gaseous engine-out emissions upwards and downwards the DOC as well as the EGR rate. A settling chamber was placed after the DOC as a way to attenuate the exhaust flow before the EGR bypass. A pneumatic valve was placed at the end of the exhaust line to reproduce the 
backpressure caused by the turbine in the real multi-cylinder engine. Finally, an AVL $415 \mathrm{~S}$ smoke meter was used to measure the smoke emissions in filter smoke number units.

\subsection{Test campaign}

Two kind of tests were performed to figure out the ability of the nominal DOC to abate raw CO and HC under representative RCCI combustion boundary conditions. Firstly, a low-temperature operating point was tested and monitored in a continuous way till tailpipe $\mathrm{HC}$ emissions and DOC outlet gas temperature were steady. This test was targeted to characterise the $\mathrm{HC}$ adsorption process and the reaction rate of high reactivity $\mathrm{HC}$ compounds. To do that, the first step consisted of operation with CDC at high speed during 20 minutes to increase the DOC inlet temperature up to $350^{\circ} \mathrm{C}$ in order to purge the monolith from any adsorpted HC. Afterwards, 10 additional minutes were run in motoring conditions to cool down the catalyst device. Finally, a thermal transient test defined by idle conditions at $2000 \mathrm{rpm}$ was run. The procedure was repeated twice in order to check the engine repeatability and measure the DOC inlet and outlet emissions alternatively in every test.

Next, the DOC response was evaluated under steady-state conditions in a series of operating points of increasing engine speed and load. The operating conditions are defined in Table 5, where the gasoline fraction is included:

$$
G F=\frac{\dot{m}_{\text {gasoline }}}{\dot{m}_{\text {gasoline }}+\dot{m}_{\text {diesel }}}
$$

Before every round, the DOC was warmed up again to release any accumulated $\mathrm{HC}$ and then driven to engine motoring during $10 \mathrm{~min}$ for thermal stabilisation. This procedure was repeated after operating point \#E. Every point was kept during $120 \mathrm{~s}$ and the measurement performed during the last $10 \mathrm{~s}$. The test was performed twice following the same sequence to provide a figure of inlet and outlet DOC pollutants mass fraction.

\section{Diesel oxidation catalyst model}

A lumped DOC model [32] has been applied in this work to complete the analysis of the experimental data. The model concept is based on a modular approach covering pressure drop, heat transfer and chemical mechanism processes. As a lumped model, constant flow properties are assumed along the monolith length thus providing a mean-value description of the substrate properties besides the prediction of the flow conditions at the catalyst outlet.

Since this work focuses on the analysis of the pollutants conversion efficiency, heat transfer and chemical processes are treated directly imposing inlet flow properties, i.e. mass flow, composition, pressure and temperature, as boundary conditions. Heat transfer is solved applying a lumped nodal scheme adapted from a 1D modelling approach [34] that accounts for the gas to wall heat exchange, the heat losses towards the environment and the thermal inertia of the monolith substrate and the external canning. The nodal schemes corresponding to the monolith and the external canning are sketched in Figure 3. 
Table 5: Tested single-cylinder engine steady-state operating points.

\begin{tabular}{|c|c|c|c|c|c|}
\hline & {$[\mathrm{rpm}]$} & {$[\mathrm{Nm}]$} & {$[\%]$} & $\begin{array}{c}\text { Exhaust } \\
\text { mass flow } \\
{[\mathrm{kg} / \mathrm{s}]}\end{array}$ & $\begin{array}{c}\text { DOC inlet } \\
\text { temperature } \\
{\left[{ }^{\circ} \mathrm{C}\right]}\end{array}$ \\
\hline \#A & 1000 & 0 & 54 & 18.49 & 115.4 \\
\hline$\# \mathrm{~B}$ & 1000 & 1.1 & 52 & 19.28 & 126.7 \\
\hline \#C & 1000 & 3.6 & 63 & 22.77 & 146.0 \\
\hline$\# \mathrm{D}$ & 1000 & 7.3 & 69 & 20.70 & 161.1 \\
\hline$\# \mathrm{E}$ & 1000 & 10.8 & 75 & 22.65 & 183.3 \\
\hline$\# \mathrm{~F}$ & 2000 & -2.2 & 57 & 35.43 & 139.6 \\
\hline$\# \mathrm{G}$ & 2000 & -0.6 & 54 & 35.10 & 155.1 \\
\hline$\# \mathrm{H}$ & 2000 & 1.8 & 57 & 35.37 & 174.6 \\
\hline$\# \mathrm{I}$ & 2000 & 4.7 & 61 & 35.12 & 194.8 \\
\hline$\# \mathrm{~J}$ & 2000 & 7.5 & 67 & 35.12 & 213.2 \\
\hline$\# \mathrm{~K}$ & 2000 & 9.7 & 70 & 35.53 & 227.3 \\
\hline$\# \mathrm{~L}$ & 2000 & 12.5 & 74 & 36.81 & 247.7 \\
\hline$\# \mathrm{M}$ & 3000 & -1.4 & 54 & 45.50 & 213.2 \\
\hline$\# \mathrm{~N}$ & 3000 & 0.4 & 53 & 45.72 & 233.0 \\
\hline$\# \mathrm{O}$ & 3000 & 2 & 56 & 44.66 & 250.3 \\
\hline$\# \mathrm{P}$ & 3000 & 4.9 & 60 & 45.16 & 271.5 \\
\hline \#Q & 3000 & 6.4 & 60 & 44.71 & 288.9 \\
\hline$\# \mathrm{R}$ & 3000 & 8.7 & 63 & 55.18 & 308.5 \\
\hline
\end{tabular}
differences:

$$
\begin{aligned}
& \rho c_{p} \frac{T_{i, j}^{p+1}-T_{i, j}^{p}}{\Delta t}=\kappa\left(\frac{T_{i-1, j}^{p}-2 T_{i, j}^{p}+T_{i+1, j}^{p}}{(\Delta x)^{2}}+\right. \\
&\left.\frac{T_{i, j-1}^{p}-2 T_{i, j}^{p}+T_{i, j+1}^{p}}{(\Delta y)^{2}}\right)+\dot{q}_{r}^{\prime \prime}
\end{aligned}
$$

Assuming axial and radial heat transfer, the wall temperature at time-step $p+1$ and node $(i, j)$ is obtained from the gas temperature and the substrate-canning conditions at the previous time-step $p$. Taking into account the definition of every control volume, i.e. thermal properties and heat transfer area, the substrate temperature in every monolith node is finally computed as: 
a) Catalyst nodal scheme

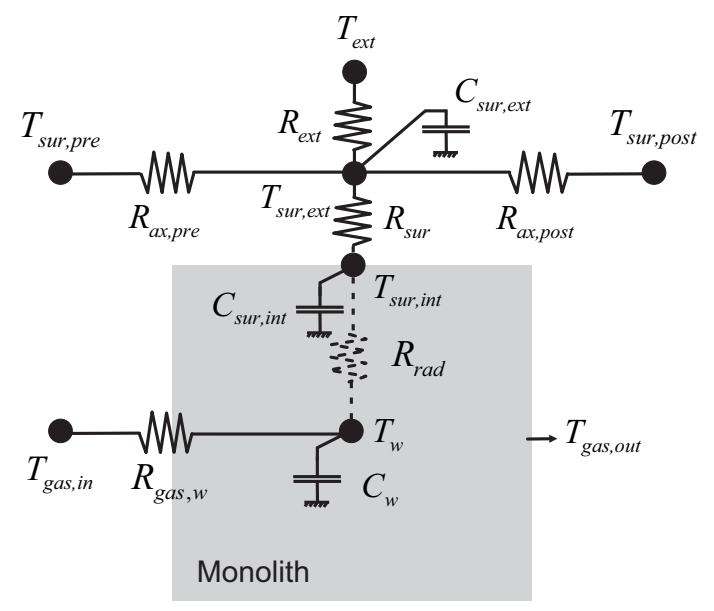

b) Canning equivalent thermal resistance

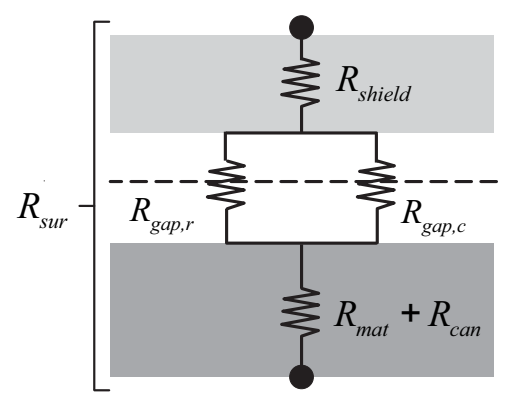

Figure 3: Nodal scheme of the heat transfer sub-model for the monolith and the external canning.

$$
T_{i, j}^{p+1}=\frac{\Delta t}{C_{i, j}}\left(\sum_{k=-1}^{+1} \frac{T_{i+k, j}^{p}-T_{i, j}^{p}}{R_{i+k, j / i, j}}+\sum_{k=-1}^{+1} \frac{T_{i, j+k}^{p}-T_{i, j}^{p}}{R_{i, j+k / i, j}}+\dot{q}_{r}\right)+T_{i, j}^{p}
$$

In Eq. (3), $C_{i, j}$ represents the thermal capacity in the control volume of node $(i, j)$ and $R$ is the equivalent thermal resistance between two neighbouring nodes, whether gas, substrate or canning. The term $\dot{q}_{r}$ is related to the heat power of the chemical reactions, so that it is just considered to predict the substrate temperature.

According to the lumped nodal scheme shown in Figure 3(a), a representative substrate wall temperature $\left(T_{w}\right)$ is calculated with the aim to provide the outlet gas temperature with a single-channel modelling approach. The lack of axial resolution for gas avoids it for substrate temperature. However, radial heat transfer is considered to account for the averaged wall temperature gradient towards the monolith periphery, where the internal surface temperature $\left(T_{\text {sur,int }}\right)$ is computed. The heat transfer across the external canning is calculated from this boundary node to determine the external surface temperature $\left(T_{\text {sur,ext }}\right)$, which is dependent on the canning layers (mat, can, air gap, thermal shield), the surrounding elements and the ambient temperature. From the definition of the thermal equivalent resistances and 
capacitances shown in Figure 3(a) and (b) and detailed in [32], the substrate and canning temperature can be obtained as:

$$
\begin{aligned}
& T_{w}^{p+1}=\frac{\Delta t}{C_{w}^{p}}\left(\sum_{k} \frac{T_{k}-T_{w}^{p}}{R_{k}}+\dot{q}_{r}^{p}\right)+T_{w}^{p} \\
& T_{\text {sur, int }}^{p+1}=\frac{\Delta t}{C_{\text {sur, }, \text { int }}^{p}}\left(\frac{T_{w}^{p}-T_{\text {sur,int }}^{p}}{R_{\text {rad }}^{p}}+\frac{T_{\text {sur }, \text { ext }}^{p}-T_{\text {sur, int }}^{p}}{R_{\text {sur }}^{p}}\right) \\
& +T_{\text {sur,int }}^{p} \\
& T_{\text {sur }, \text { ext }}^{p+1}=\frac{\Delta t}{C_{\text {sur, ext }}^{p}}\left(\frac{T_{\text {ext }}-T_{\text {sur,ext }}^{p}}{R_{\text {ext }}^{p}}+\frac{T_{\text {sur, int }}^{p}-T_{\text {sur,ext }}^{p}}{R_{\text {sur }}^{p}}+\right. \\
& \left.\frac{T_{\text {sur }, \text { pre }}^{p}-T_{\text {sur }, \text { ext }}^{p}}{R_{a x, p r e}^{p}}+\frac{T_{\text {sur,post }}^{p}-T_{\text {sur }, e x t}^{p}}{R_{a x, p o s t}^{p}}\right)+T_{\text {sur,ext }}^{p}
\end{aligned}
$$

The DOC model computes the variation in gas composition along the catalyst monolith caused by the $\mathrm{CO}$ and $\mathrm{HC}$ oxidation as well as the physisorption of $\mathrm{HC}$ on the zeolites present in the washcoat:

$$
\begin{gathered}
\mathrm{CO}+\frac{1}{2} \mathrm{O}_{2} \rightarrow \mathrm{CO}_{2} \\
\mathrm{C}_{n} \mathrm{H}_{m}+\left(n+\frac{m}{4}\right) \mathrm{O}_{2} \rightarrow n \mathrm{CO}_{2}+\frac{m}{2} \mathrm{H}_{2} \mathrm{O} \\
\mathrm{C}_{n} \mathrm{H}_{m}+\mathrm{Zeol} . \rightleftarrows \mathrm{C}_{n} \mathrm{H}_{m} \bullet \mathrm{Zeol} .
\end{gathered}
$$

The oxidation of $\mathrm{HC}$ has been modelled distinguishing between low and high reactivity compounds. It provides more accuracy in the definition of the light-off temperature region. Decane and toluene have been considered in this work as representative species of the engine raw emission. The choice of these species is based on the RCCI HC speciation provided by Storey et al. [27] for the case of UTG \& ULSD combination, which is a similar scenario to the one analysed in this work.

The $\mathrm{CO}$ and $\mathrm{HC}$ conversion efficiency is determined solving the one-dimensional chemical species transport equations in the bulk gas and washcoat regions. Quasi-steady flow is assumed within the monolith, so that one has

$$
\begin{gathered}
u_{i n} \frac{d X_{n}}{d x}=-S_{p, c a t} k_{m, n}\left(X_{n}-X_{n, w c}\right) \\
\sum_{j} v_{n} R_{j, n}+S_{p, w c} k_{m, n}\left(X_{n}-X_{n, w c}\right)=0
\end{gathered}
$$


where Eq. (10) regards the bulk gas equation and Eq. (11) represents the chemical species transport in the washcoat of the pollutant species $n$, i.e. $\mathrm{CO}$, high reactivity $\mathrm{HC}$ and low reactivity $\mathrm{HC}$. The bulk gas transport equation covers the convective transport of the species along the monolith channels and its diffusion towards the washcoat interface. The diffusion is affected by the catalyst specific surface, which is defined as the catalytic surface and the bulk gas volume ratio, and the bulk mass transfer coefficient. According to Eq. (11), the gaseous species are then transported by diffusion from the washcoat interface to its internal volume, where the reaction takes place. The diffusion rate is determined by the washcoat specific surface, which is defined by the catalytic surface to the washcoat volume.

The bulk mass transfer coefficient governs the variations in the diffusion rate as a function of the operating conditions. It is determined by the flow properties and the channel cross-section geometry as

$$
k_{m, n}=\frac{D_{m, n} \mathrm{Sh}_{\mathrm{n}}}{\alpha},
$$

being the Sherwood number defined as proposed by Hawthorn [35]

$$
\mathrm{Sh}_{\mathrm{n}}=\mathrm{Sh}_{\infty}\left(1+\frac{0.095 \mathrm{D}_{\mathrm{h}} \mathrm{ReSc}_{\mathrm{n}}}{\mathrm{L}_{\text {mon }}}\right)^{0.45}
$$

where $\mathrm{Sh}_{\infty}$ takes the value 3.656 for circular cross-section channels. This cross-section is approximated from the original square channel cross-section to consider the deposition of the washcoat layer. The molecular diffusivity in the gas mixture of species $n$ is calculated from its individual molecular diffusivity with every species $k$ and the gas composition as [36]:

$$
D_{m_{n, k}}=\frac{1.43 \times 10^{-6} \frac{T^{1.75}}{p}}{\sqrt{\frac{M_{n}+M_{k}}{0.002}}\left(v_{n}^{\frac{1}{3}}+v_{k}^{\frac{1}{3}}\right)^{2}} \rightarrow D_{m, n}=\left(\sum_{k} \frac{X_{k}}{D_{m_{n, k}}}\right)^{-1}
$$

The reaction rate for every pollutant species accounts for all reactions in which is involved. It takes different form as a function of the reaction type. The reaction rate term for the $\mathrm{CO}$ and $\mathrm{HC}$ oxidation is modelled as

$$
R_{o x, n}=\eta_{\text {int }, o x, n} \frac{k_{o x, n}}{G_{o x}} X_{O_{2}} X_{n, w c}
$$

where $n$ refers to the pollutant species. The kinetic constant is an Arrhenius type equation dependent on the substrate wall temperature. The competition between species is considered by means of the inhibition term, which is defined for $\mathrm{CO}$ and $\mathrm{HC}$ oxidation according to the proposal of Oh and Cavendish [37] as

$$
\begin{aligned}
G_{o x} & =T_{w}\left(1+K_{1} X_{C O, w c}+K_{2}\left(\sum_{i} X_{H C_{i}, w c}\right)\right)^{2} \\
& \left.\left(1+K_{3} X_{C O, w c}^{2}\left(\sum_{i} X_{H C_{i}, w c}\right)^{2}\right)\left(1+K_{4} X_{N O, w c}^{0.7}\right)\right),
\end{aligned}
$$

where the subscript $i$ distinguishes the low and high reactivity HC species. 
The adsorption and desorption processes involving gas and zeolite sites on the washcoat are modelled taking into account the amount of accumulated $\mathrm{HC}$ every time-step. This is done considering the surface coverage $\left(\theta_{H C}\right)$ and the specific storage capacity of the washcoat $\left(\psi_{H C}\right)$ :

$$
\begin{gathered}
R_{a d s, H C_{i}}=\eta_{\text {int,ads }, H C_{i}} k_{a d s, H C, i}\left(1-\theta_{H C_{i}}\right) \psi_{H C} X_{H C_{i}, w c} \\
R_{d e s, H C_{i}}=\eta_{i n t, d e s, H C_{i}} k_{d e s, H C_{i}} \theta_{H C} \psi_{H C}
\end{gathered}
$$

All the reaction rates are accounting for diffusion limitation. It is done correcting the kinetic constant with the internal pore diffusion efficiency term $\left(\eta_{i n t, r, n}\right)$, which is obtained as a function of the Thiele modulus [38]:

$$
\eta_{i n t, r, n}=\frac{1}{\varphi_{r, n}}\left(\frac{1}{\tanh \left(3 \varphi_{r, n}\right)}-\frac{1}{3 \varphi_{r, n}}\right)
$$

The Thiele modulus is defined for a catalyst slab corresponding to the washcoat layer thickness as [39]

$$
\varphi_{r, n}=w_{w c} \sqrt{\frac{k_{r, n} \prod_{j} X_{j}^{m_{j}}}{G_{r, n} D_{e f, n} X_{n}}}
$$

where $D_{e f, n}$ is the effective diffusivity of the species $n$ [40]:

$$
D_{e f, n}=\frac{\varepsilon_{w c}}{\zeta_{w c}}\left(\frac{1}{D_{m, n}}+\frac{1}{D_{\mathrm{Kn}, \mathrm{n}}}\right)^{-1}
$$

In Eq. (21) the Knudsen diffusivity is calculated according to [38]

$$
D_{\mathrm{Kn}, \mathrm{n}}=\frac{d_{p, w c}}{3} \sqrt{\frac{8 \Re T}{\pi \overline{M_{n}}}}
$$

where $d_{p, w c}$ represents the characteristic pore diameter of the meso-pores in the catalyst washcoat.

Once described the different parameters in Eqs. (10) and (11), the outlet concentration can be obtained for every pollutant species by combining them. Taking into account first-order reactions, i.e. $\mathrm{CO} / \mathrm{HC}$ oxidation and $\mathrm{HC}$ adsorption, and zero-order reactions, i.e. HC desorption, the washcoat concentration of species $n$ can be expressed from Eq. (11) as:

$$
X_{n, w c}=\frac{\sum_{j} v_{j, n}^{1} R_{j, n}^{1}\left(X_{n, w c}\right)+\sum_{j} v_{j, n}^{0} R_{j, n}^{0}+S_{p, w c} k_{m, n} X_{n}}{S_{p, w c} k_{m, n}}
$$

Since first-order reactions are dependent on the washcoat pollutant concentration, rearranging one finally obtains a linear dependence on the bulk gas concentration,

$$
X_{n, w c}=a_{n} X_{n}+b_{n},
$$


that for the particular case of $\mathrm{CO}$ and $\mathrm{HC}$ can be written as:

$$
\begin{gathered}
X_{C O, w c}=\frac{S_{p, w c} k_{m, C O}}{S_{p, w c} k_{m, C O}-\eta_{\text {int,ox,CO } \frac{k_{o x}, C O}{G_{o x}, C O}} X_{O_{2}}} X_{C O} \\
X_{H C_{i}, w c}=\frac{S_{p, w c} k_{m, H C_{i}} X_{H C_{i}}+\eta_{\mathrm{int}, d e s, H C_{i}} k_{d e s, H C_{i}} \theta_{H C} \psi_{H C}}{S_{p, w c} k_{m, H C_{i}}+\eta_{\mathrm{int}, o x, H C_{i}} \frac{k_{x o x, H C_{i}}}{G_{o x, H C_{i}}} X_{O_{2}}+\eta_{\text {int }, a d s, H C_{i}} k_{a d s, H C_{i}}\left(1-\theta_{H C}\right) \psi_{H C}}
\end{gathered}
$$

In Eq. (24), $a_{n}$ is a coefficient related to first-order reactions and $b_{n}$ to zero-order ones. According to Eqs. (25) and (26), these coefficients are constant in $\mathrm{CO}$ and $\mathrm{HC}$ solutions if the $\mathrm{O}_{2}$ concentration is assumed constant along the catalyst monolith. This hypothesis is valid under lean combustion conditions due to the high $\mathrm{O}_{2}$ concentration in the exhaust mass flow in comparison to $\mathrm{CO}$ and $\mathrm{HC}$ [32]. Therefore, the outlet concentration of species $n$ is finally determined by substitution of Eq. (24) into Eq. (10) and integrating into the time-step,

$$
\begin{aligned}
\int_{0}^{L_{m o n}} \frac{d x}{u_{\text {in }}} & =\int_{X_{n, \text { in }}}^{X_{n, \text { out }}} \frac{d X_{n}}{-S_{p, c a t} k_{m, n}\left(1-a_{n}\right) X_{n}+S_{p, c a t} k_{m, n} b_{n}} \\
X_{n, \text { out }} & =\frac{\left(\left(1-a_{n}\right) X_{n, \text { in }}-b_{n}\right) e^{-S_{p, c a t} k_{m, n}\left(1-a_{n}\right) \tau}+b_{n}}{\left(1-a_{n}\right)}
\end{aligned}
$$

where $\tau$ is the residence time.

The outlet gas composition can be expressed in mass fraction terms relating the inlet mass fraction of every species $k$ with the variation in mass fraction of reactants and products as follows

$$
Y_{k, \text { out }}=\frac{\dot{m}_{k, \text { out }}}{\dot{m}_{\text {out }}}=\frac{\dot{m}_{k, \text { in }}+\dot{m}_{\text {in }} \Delta Y_{k}}{\dot{m}_{\text {in }}\left(1+\sum \Delta Y_{i}\right)}=\frac{Y_{k, \text { in }}+\Delta Y_{k}}{1+\sum \Delta Y_{i}},
$$

where the mass fraction variation of the non-pollutant species is calculated from the stoichiometry of every chemical reaction:

$$
\Delta Y_{k}=-\frac{M_{k}}{\bar{M}} \sum_{j} v_{k, j} \Delta X_{j, k}
$$

In Eq. (30) $M_{k}$ and $\bar{M}$ are the molecular weights of the species $k$ and the gas mixture respectively, $v_{k, j}$ is the stoichiometric coefficient of the species $k$ in the reaction with pollutant $j$ and $\Delta X_{j, k}$ represents the molar fraction variation of the pollutant $j$ in the reaction involving species $k$ in its conversion.

The variation in molar fraction and surface coverage due to the chemical mechanism allows calculating the released heat per unit of time onto the washcoat:

$$
\dot{q}_{r}=\dot{n}_{g a s} \sum_{j} H_{f, j} \Delta X_{j}+\Psi_{H C} \frac{\Delta H_{H C, \frac{a d s}{d s}} \Delta \theta_{H C}}{\Delta t}
$$

The main contribution to the heat released is that coming from the gas phase reactions. It is a function of the total exhaust gas mole flow entering the catalyst, the enthalpy of formation of the species $j$ and its molar fraction variation 
during the time-step due to the gas phase reactions. The second term regards the $\mathrm{HC}$ adsorption and desorption, which are dependent on the stored $\mathrm{HC}$ mole variation, i.e. a function of the $\mathrm{HC}$ storage capacity and the surface coverage variation, and the heat of $\mathrm{HC}$ adsorption-desorption.

The remaining outlet gas properties are obtained combining the results coming from the pressure drop, heat transfer and chemical sub-models. Thus, the mass and energy balance between the inlet and outlet sections of the monolith are solved every time-step to establish the outlet velocity and gas temperature:

$$
\begin{gathered}
u_{\text {out }}=\frac{A_{\text {in }} u_{\text {in }} p_{\text {in }} T_{\text {out }}}{A_{\text {out }} p_{\text {out }} T_{\text {in }}} \\
T_{\text {out }}=\frac{c_{p, \text { in }}}{c_{p, \text { out }}} T_{\text {in }}-\frac{\dot{q}_{h t}}{\dot{m} c_{p, \text { out }}}+\frac{u_{\text {in }}^{2}-u_{\text {out }}^{2}}{2 c_{p, \text { out }}}
\end{gathered}
$$

\section{Results and discussion}

This section is devoted to the analysis of the results combining the experimental and modelled data. The HC adsorption and the impact of the RCCI boundaries on the DOC conversion efficiency covering both engine steady conditions and theoretical light-off curves are discussed.

\subsection{Hydrocarbons adsorption test}

Firstly, the low temperature transient test was used to calibrate the model with respect to the adsorption process, i.e. adsorption kinetics as well as the washcoat accumulation capacity. Figure 4 shows the main magnitudes defining the test. Despite the low exhaust gas temperature to promote the $\mathrm{HC}$ adsorption, which is kept below $150{ }^{\circ} \mathrm{C}$ as shown in Figure 4(a), a small portion of $\mathrm{HC}$ and $\mathrm{CO}$ were also oxidised once the DOC inlet temperature was stabilised. It is evidenced by plots (b) and (c) in Figure 4, which represent the difference in inlet and outlet mass fraction and the conversion efficiency for both pollutants respectively. As shown in Figure 4(a), the oxidation leads the experimental outlet gas temperature over the inlet one after $300 \mathrm{~s}$. Despite a minor deviation, this response is well captured by the model in agreement with the results provided in conversion efficiency. This reaches $20 \%$ for $\mathrm{HC}$ and scarcely $8 \%$ for $\mathrm{CO}$ at the end of the test. This low conversion efficiency of $\mathrm{CO}$ and $\mathrm{HC}$ was useful to define the kinetic constants of $\mathrm{CO}$ and high reactivity $\mathrm{HC}$, which are the ones assumed being oxidised. In that sense, the portion of the high reactivity $\mathrm{HC}$ in the test was set to $20 \%$ of the total $\mathrm{HC}$ (THC) mass fraction. As described, this value coincides with the steady-state THC conversion efficiency, which is represented in Figure 4(c). The main parameters used in the modelling of the DOC conversion efficiency are shown in Table 6. Concerning HC, the pre-exponential factors and activation energies corresponding to adsorption and desorption were calibrated without distinction of $\mathrm{HC}$ species. Otherwise, the oxidation modelling distinguishes between high reactivity species, whose properties were set by the thermal transient test, and low reactivity compounds, whose reactivity was defined by the steady-state tests discussed in Section 4.2. 
Table 6: DOC simulation parameters.

\begin{tabular}{lcc}
\hline \multicolumn{3}{c}{ Kinetic constants } \\
\hline & $\mathrm{P}_{\mathrm{f}}\left[\mathrm{s}^{-1}\right]$ & $\mathrm{E}_{\mathrm{a}}[\mathrm{J} / \mathrm{mol}]$ \\
\hline$H C$ adsorption & 0.95 & 0 \\
$H C$ desorption & 3000 & 105000 \\
$H C_{\text {low-react }}$ oxidation & $9 \times 10^{16}$ & 100500 \\
$H C_{\text {high-react }}$ oxidation & $8 \times 10^{20}$ & 95000 \\
$C O$ oxidation & $8 \times 10^{17}$ & 87000 \\
\hline \multicolumn{4}{c}{ Inhibition terms } \\
\hline$K_{1}$ & $\mathrm{P}_{\mathrm{f}}[-]$ & $\mathrm{E}_{\mathrm{a}}[\mathrm{J} / \mathrm{mol}]$ \\
$K_{2}$ & 555 & $-7990[37]$ \\
$K_{3}$ & $1.58 \times 10^{3}$ & $3 \times 10^{3}[37]$ \\
$K_{4}$ & 2.98 & $-96534[37]$ \\
\hline \multicolumn{3}{c}{ Washcoat properties } \\
\hline$\psi_{H C}\left[\mathrm{~mol} / \mathrm{m}^{3}\right]$ & & $31036[37]$ \\
$w_{w c}[\mu \mathrm{m}]$ & & 300 \\
$\varepsilon_{w c}[-]$ & & $30[41]$ \\
$\zeta_{w c}[-]$ & & $0.5[42]$ \\
$d_{p, w c}[\mathrm{~nm}]$ & & $352]$ \\
\hline \hline
\end{tabular}

As observed in Figure 4(c), the early part of the test shows a decreasing THC conversion efficiency. It converges to a steady-state value due to the remaining high reactivity HC oxidation. This behaviour is governed by the increase in gas temperature but also because of the increase in surface coverage due to HC adsorption. The increase of these magnitudes makes the abatement mechanism move from adsorption to oxidation. For the sake of completeness, Figure 5 represents the HC surface coverage and the variation in THC mass fraction due to adsorption and oxidation separately ( $<0$ for adsorption and oxidation, $>0$ for desorption). The rate of increase of the surface coverage, which agrees with the decreasing rate in THC mass fraction variation due to adsorption, is slowed down along the test. The washcoat is completely saturated from $300 \mathrm{~s}$ on, what underlines the limitations of a standard DOC to deal with RCCI HC adsorption needs in comparison to CDC conditions, which are characterised for lower raw THC emission. Complementary, the THC mass fraction variation due to oxidation starts at $125 \mathrm{~s}$, when the inlet gas temperature reaches $135^{\circ} \mathrm{C}$, and increases till the inlet gas temperature stabilisation, i.e. time $300 \mathrm{~s}$.

\subsection{Conversion efficiency in steady-state conditions}

Figure 6 shows contour plots corresponding to the experimental raw $\mathrm{CO}$ and THC mass fraction and conversion efficiency under steady-state operation. The black dots represent the tested operating points previously defined in 
a)

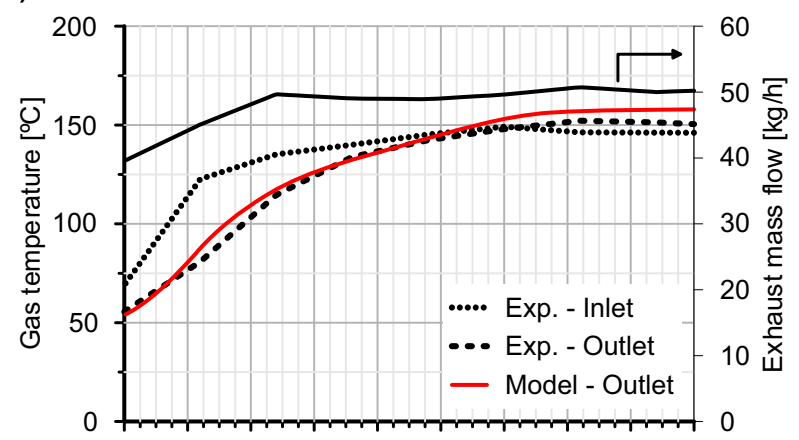

b)

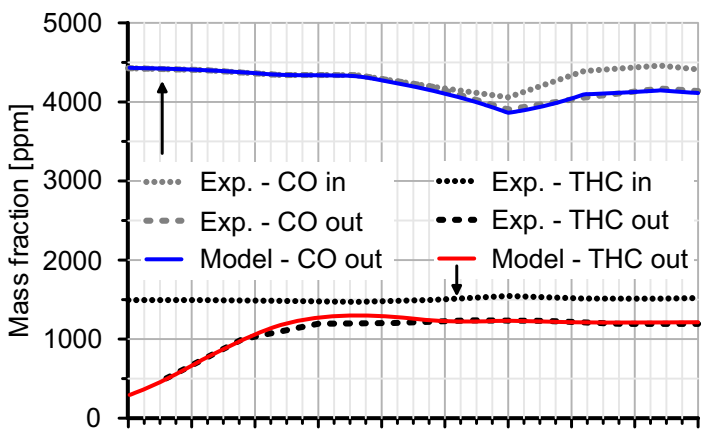

c)

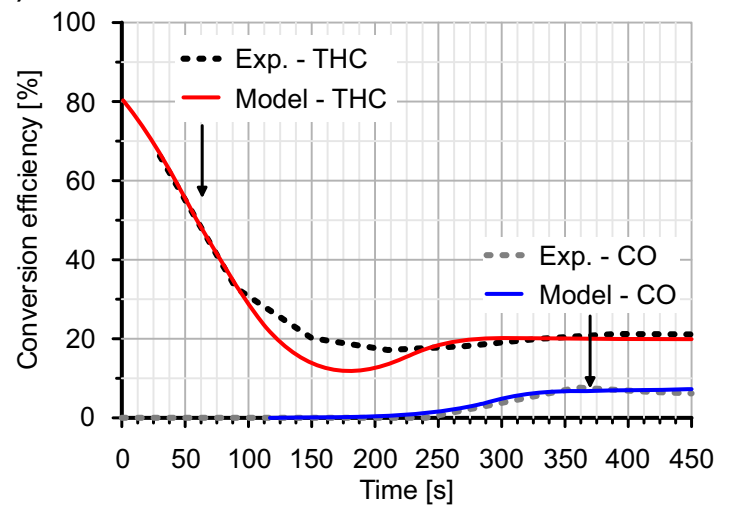

Figure 4: Comparison between experimental and modelled data during the thermal transient test (idle @ $2000 \mathrm{rpm}$ ).

Table 5. As depicted in plots (a) and (b) in Figure 6, high raw CO and THC mass fraction is found in the whole tested range. The raw $\mathrm{CO}$ emission evidences sensitivity to engine load, so that it undergoes a fast increase as the exhaust gas temperature decreases. In particular, the raw CO emission reaches $7229 \mathrm{ppm}$ in point \#A, which will be considered as a representative point for next analysis. Otherwise, the raw THC mass fraction is kept below 1400 ppm in most of the map but showing a clear increase in points at $3000 \mathrm{rpm}$, which correspond to the high mass flow region.

Despite the high raw CO and THC emissions, the DOC conversion efficiency is higher than $90 \%$ over $150{ }^{\circ} \mathrm{C}$ for $\mathrm{CO}$ and $160^{\circ} \mathrm{C}$ for $\mathrm{THC}$ at low mass flow. These reference temperatures increase as the mass flow does due 


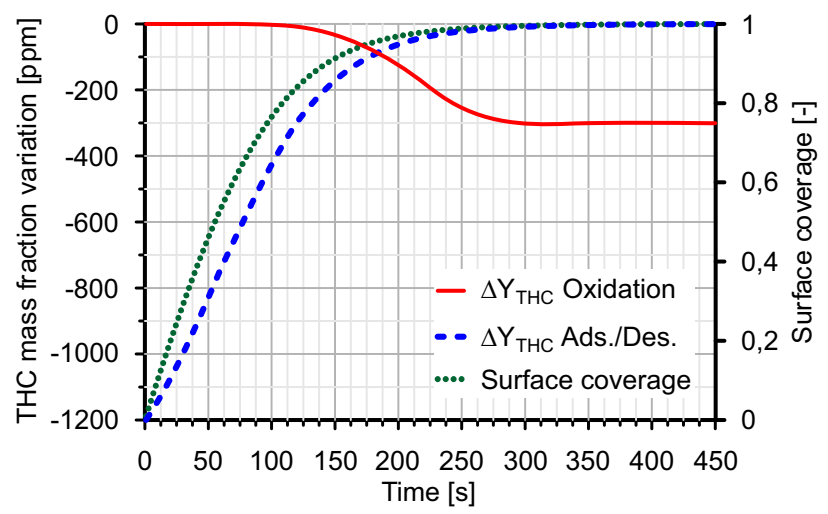

Figure 5: THC mass fraction variation due to adsorption and oxidation processes during the thermal transient test (idle @ 2000 rpm).

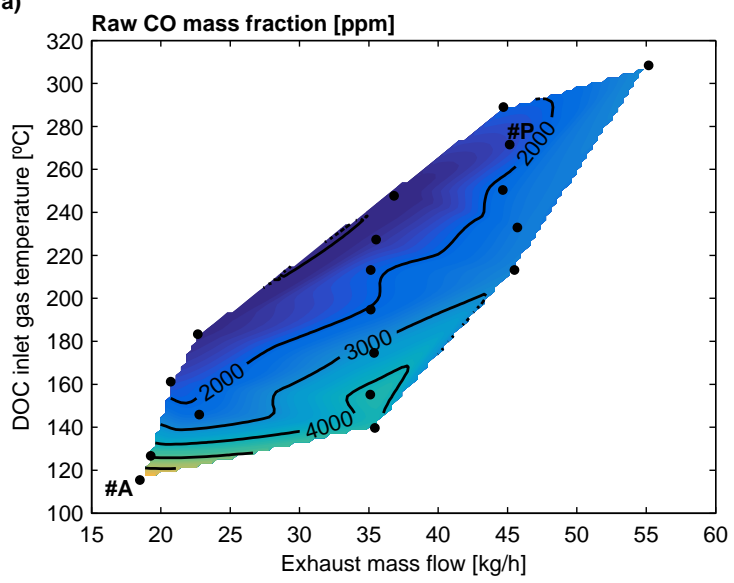

c)

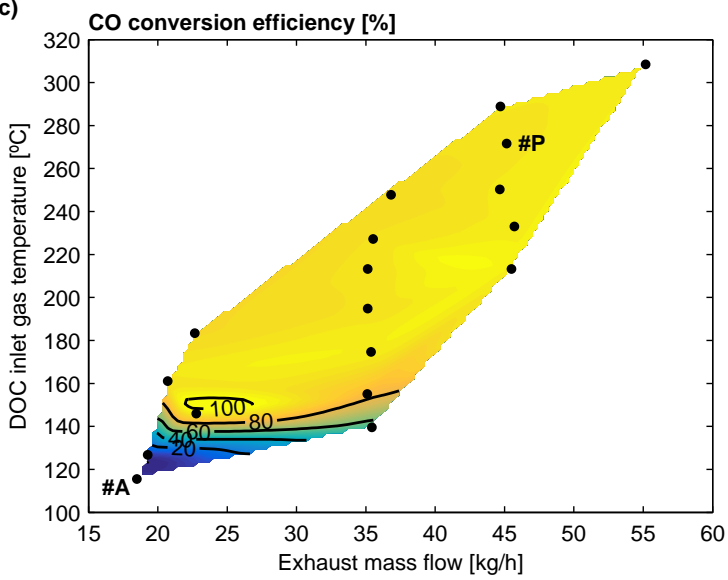

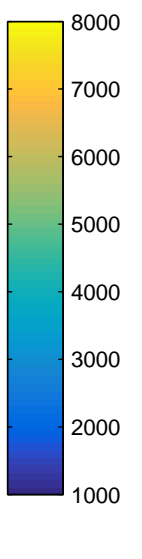
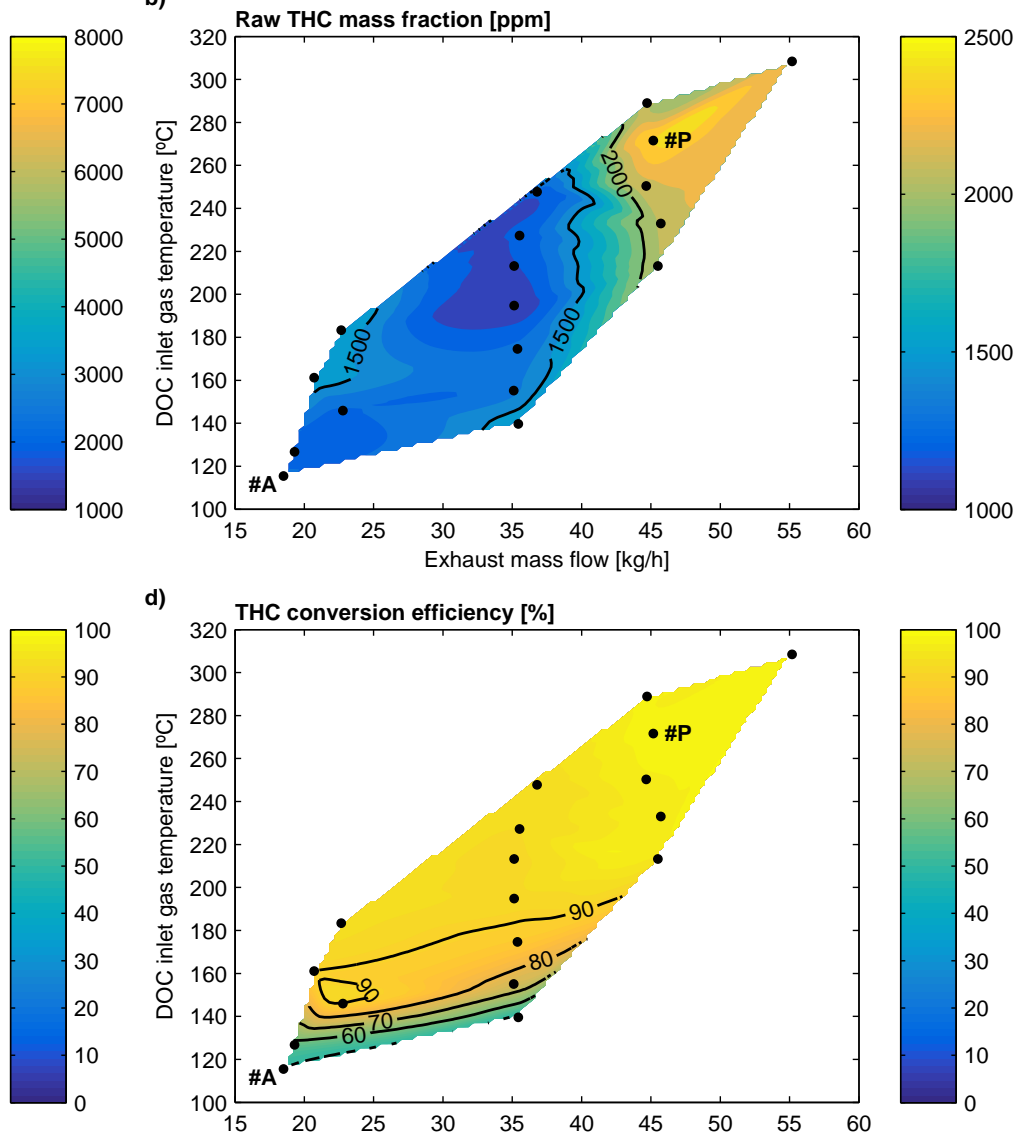

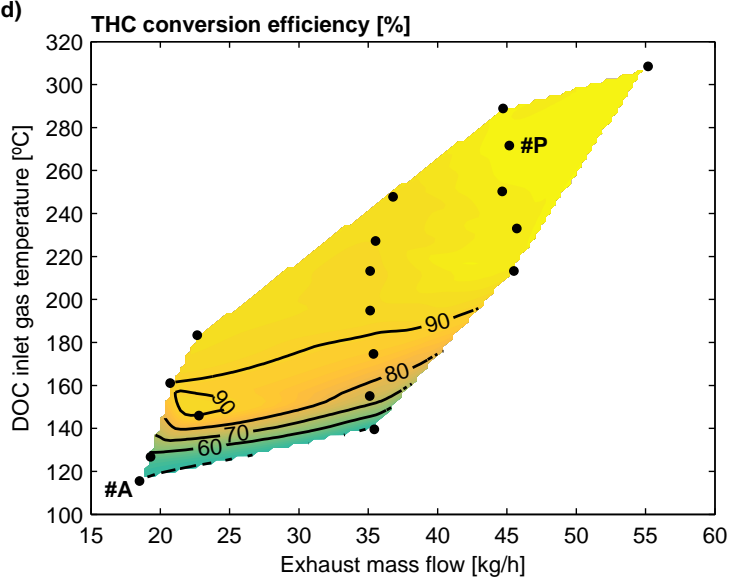

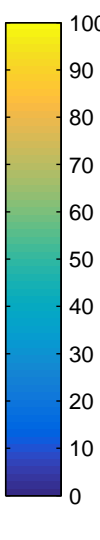

Figure 6: Experimental raw $\mathrm{CO}$ and THC emission and conversion efficiency under steady-state conditions. 
to the residence time reduction inside the catalyst. Below $90 \%$, the conversion efficiency is highly sensitive to gas temperature. This is especially relevant for $\mathrm{CO}$ oxidation since the THC conversion efficiency becomes governed by the adsorption contribution in the low temperature region. In the case of $\mathrm{CO}$, this region corresponds with the light-off temperature range and is also conditioned by relevant $\mathrm{CO}$ inhibition. As previously described, the raw $\mathrm{CO}$ emission increases in this operating region, what makes the oxidation inhibition term increase according to Eq. (16).

Figure 7 shows the comparison between experimental and modelled DOC outlet temperature in plot (a) and conversion efficiency for THC and CO in plots (b) and (c) respectively. In addition, the model results are extended to the multi-cylinder engine case, for which the DOC is originally sized. For the sake of simplicity, to do that the mass flow is assumed to be increased 4 times with respect to the baseline experimentally provided by the single-cylinder engine. Working under multi-cylinder conditions reduces the residence time with respect to the experiments, so that the limitations in DOC performance when combining low exhaust gas temperature and high $\mathrm{CO}$ and $\mathrm{THC}$ mass fraction arise.

The model shows good ability to predict the experimental THC (Figure 7(b)) and CO (Figure 7(c)) conversion efficiency within the whole range. Despite minor deviations in the maximum efficiency for both species, the model is completely able to capture the impact of exhaust gas temperature and mass flow at low conversion efficiency. Since the thermal response is coupled to the reaction rate, the outlet gas temperature is also accurately predicted. As observed in Figure 7(a), the increase of the DOC outlet temperature is properly reproduced according to the $\mathrm{CO}$ and THC oxidation behaviour. Operating points with maximum conversion efficiency in the DOC causes a temperature increases ranging from $75^{\circ} \mathrm{C}$ to $100^{\circ} \mathrm{C}$ due to the high raw mass fraction of both $\mathrm{THC}$ and $\mathrm{CO}$.

On this concern, it is interesting to note the lack of impact on the DOC outlet temperature in points \#A and \#B. The DOC inlet temperature in these points is below $150^{\circ} \mathrm{C}$, so that only $\mathrm{HC}$ adsorption takes place. In the case of points $\# \mathrm{~F}$ and $\# \mathrm{G}$, a slight increase in outlet gas temperature is noticed since both adsorption and oxidation are occurring simultaneously. These results are supported by Figure 8(a), which shows the contributions to HC abatement distinguishing between oxidation and adsorption/desorption in the single-cylinder engine test. The modelling results confirm that the adsorption is the main mechanism of $\mathrm{HC}$ abatement in points \#A and \#B, which hardly show oxidation of the high reactivity HC. The mass fraction of high reactivity $\mathrm{HC}$ has been assumed $20 \%$ in all the steady-state points. It is defined because of the gasoline to diesel fuel ratio, which is in the same order of magnitude in the steady-state points as in the thermal transient test $(\mathrm{GF}=60 \%)$. Contrarily to \#A and \#B, the higher temperature in points \#F and $\# \mathrm{G}$, which reach $150^{\circ} \mathrm{C}$, leads to relevant oxidation of high reactivity $\mathrm{HC}$. However, this process inhibits the adsorption. Nevertheless, the low reactivity HC is still adsorpted because of its low oxidation kinetic constant in these operating conditions. The remaining points undergo high and low reactivity HC oxidation in the DOC. Finally, the $\mathrm{HC}$ desorption is significantly noticed from point $\# \mathrm{O}$ on, i.e. once the inlet $\mathrm{DOC}$ temperature is over $250{ }^{\circ} \mathrm{C}$ and the outlet one higher than $330^{\circ} \mathrm{C}$. This result points out the interest for the DOC outlet gas temperature as a diagnostic parameter [31] since this magnitude is directly dependent on the substrate temperature, where the desorption and oxidation are taking place. Comparing different points, point $\# \mathrm{~L}$ almost reaches $250^{\circ} \mathrm{C}$ at the $\mathrm{DOC}$ inlet but its lower 

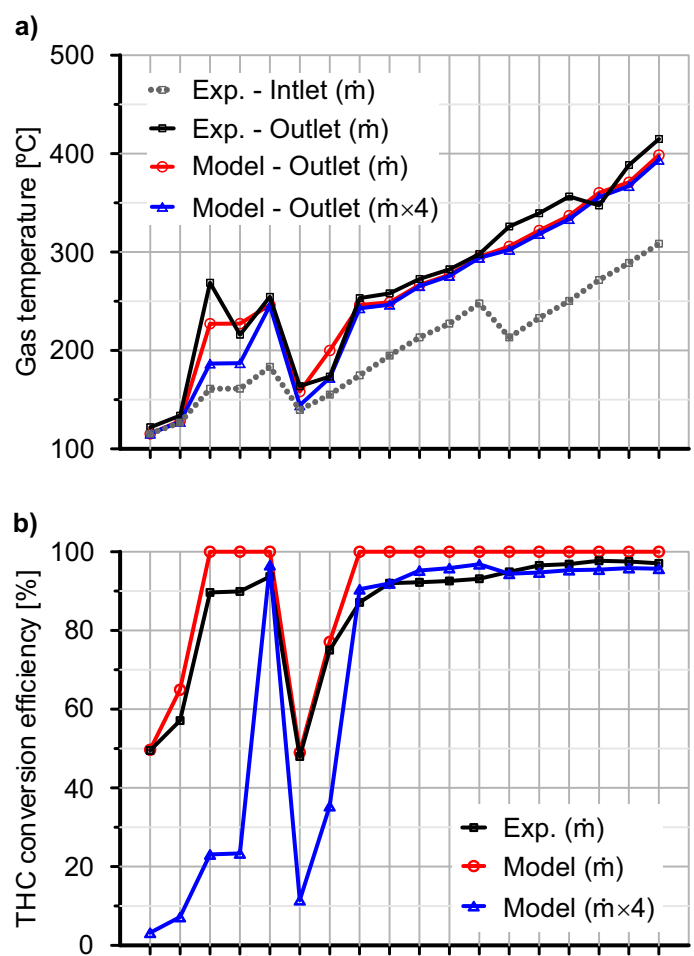

c)

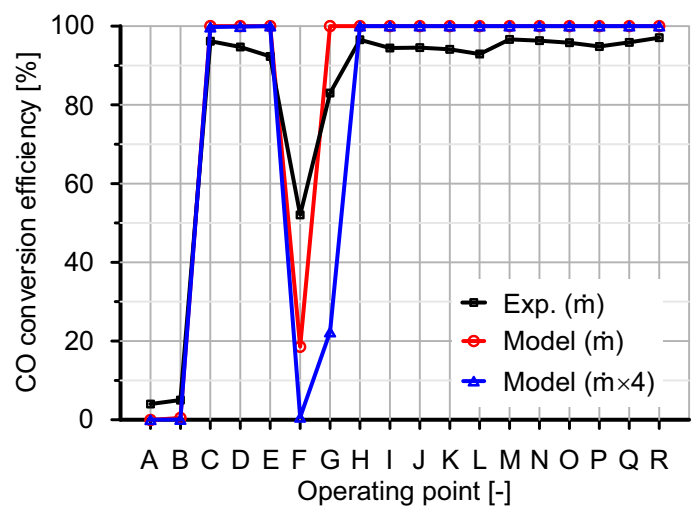

Figure 7: Comparison between experimental and modelled gas temperature and conversion efficiencies for steady-state points in single- and multicylinder engine mass flow conditions.

raw THC mass fraction in comparison to point \#O (1238 ppm vs. $2165 \mathrm{ppm})$ gives as a result $294.9^{\circ} \mathrm{C}$ in outlet gas temperature. By contrast, point \#N is characterised by $233^{\circ} \mathrm{C}$ as DOC inlet temperature but its high THC emission (2119 ppm) leads the outlet gas temperature to $321.8^{\circ} \mathrm{C}$, what already produces a very slight desorption. Nevertheless, the high temperature at which the desorption takes place ensures high oxidation rate, thus preventing HC slip.

The CO conversion efficiency shows relevant variations when the multi-cylinder engine case is considered in operating points whose temperature is close to the light-off. The operating points \#F and \#G, which can be assumed 
to have the same exhaust mass flow according to Table 5, define the range for the CO light-off temperature. In these points, the DOC inlet temperature is $139.6^{\circ} \mathrm{C}$ and $155.1^{\circ} \mathrm{C}$ respectively. The outlet gas temperature increases in both points due to $\mathrm{CO}$ and $\mathrm{HC}$ oxidation. Nonetheless, the low DOC inlet temperature in these points makes the oxidation rate decrease when the mass flow increases due to the residence time reduction. It prevents the substrate temperature from increasing significantly, so that it contributes, in turn, to reduce further the oxidation rate in a snowball effect. Consequently, the $\mathrm{CO}$ conversion efficiency drops dramatically to $0 \%$ and $20 \%$ in points \#F and \#G respectively. The drop from $100 \%$ to $20 \%$ in point \#G when the mass flow is increased highlights again the interest for DOC control based on the outlet gas temperature instead of more classical models based on residence time and inlet gas temperature [24]. Despite the fact that the effect shown here is caused by residence time variation, the outlet gas temperature is directly related to the DOC performance at the same time as it accounts for different processes, such as thermal transient or ageing, whose effects are missed by the inlet flow properties.

The mass flow increase affects the THC conversion efficiency in a similar way to $\mathrm{CO}$ abatement but with additional features due to the adsorption and oxidation interaction. Firstly, the multi-cylinder engine case makes the THC conversion efficiency decrease even in operating points of high temperature ( $-5 \%$ in efficiency), as shown in Figure 7(b). This happens because of the higher HC activation energy than CO, especially for the case of low reactivity HC. As a result, the reaction rate of these species is more sensitive to other operating parameters, such as mass flow, within a wider temperature window. Despite these remarked differences with respect to $\mathrm{CO}$, this effect is negligible in comparison to the variations that are obtained at low temperature. In this region, the mass flow increase takes more importance because of its influence on the light-off temperature and the adsorption process.

As represented in Figure 7(b), the operating points with adsorption as main HC abatement mechanism, i.e. points \#A and \#B, show a conversion efficiency below $10 \%$ when the mass flow is increased to the multi-cylinder engine case. Plot (b) in Figure 8 confirms that the adsorption and oxidation of high reactivity HC become residual. Similarly, other points originally limited in THC conversion efficiency, like \#F and \#G, also suffer a loss of abatement performance. In particular, the increase in mass flow reduces the adsorption, which is key for low reactivity hydrocarbons abatement, and the oxidation of high reactivity HC. The drop in conversion efficiency due to these mechanisms cannot be balanced by the competitive mechanism, i.e. oxidation in low reactivity $\mathrm{HC}$ and adsorption in high reactivity $\mathrm{HC}$. The reason is that the equilibrium is exclusively governed by the chemical kinetics and not influenced by the residence time. The importance of the mass flow is also evidenced in operating points whose temperature is close to the light-off. Points \#C and \#D, which are $146^{\circ} \mathrm{C}$ and $161.1^{\circ} \mathrm{C}$ in DOC inlet temperature respectively, are representative of this condition. Taking as baseline the modelling of the experimental case, which is plotted in Figure 8(a), both points \#C and \#D are characterised by the oxidation of high reactivity $\mathrm{HC}$, without adsorption. On the other hand, low reactivity $\mathrm{HC}$ is mostly oxidised but still adsorpted in a small amount. However, the increase in mass flow leads low reactivity HC to decrease its oxidation rate. It conditions the THC conversion efficiency, as observed in Figure 7(b). 
a) Single-cylinder engine case (m)

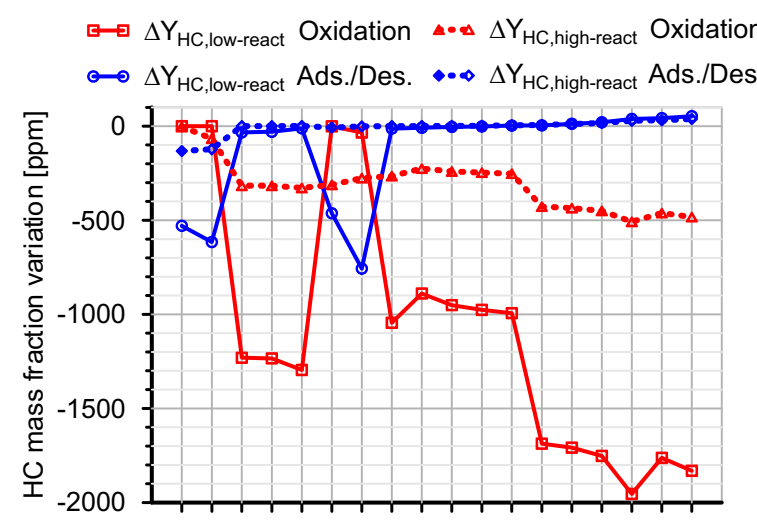

b) Multi-cylinder engine case $(\dot{\mathrm{m}} \times 4)$

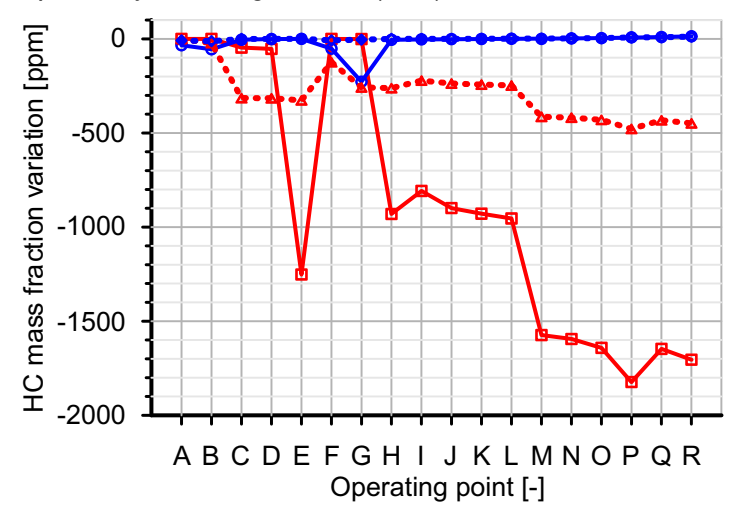

Figure 8: Contribution of $\mathrm{HC}$ abatement mechanisms under steady-state operating conditions as a function of the exhaust mass flow and the HC reactivity.

\subsection{Light-off curves}

As a complement to engine tests, a series of light-off simulations have been carried out. The HC adsorption has been neglected in order to reach a better understanding of the RCCI boundary conditions influence on the oxidation kinetics of $\mathrm{CO}$ and HC. This kind of simulation allows evaluating step by step how the mass flow and the pollutants mass fraction vary the conversion efficiency as a function of the substrate temperature. Therefore, the impact of RCCI single-and multi-cylinder engine mass flow as well as RCCI against CDC raw CO and THC mass fraction can be compared separately. To do that, two characteristic operating points from the tested matrix were selected: point \#A from the low mass flow and temperature region and point \#P from the high mass flow and temperature region. In particular, point \#A is characterised by the highest raw CO mass fraction $\left(Y_{C O \text {, in }}=7229 \mathrm{ppm}, Y_{H C \text {,in }}=1336 \mathrm{ppm}\right)$ whilst point \#P provides the highest raw THC mass fraction $\left(Y_{C O, i n}=1624 \mathrm{ppm}, Y_{H C \text {,in }}=2395 \mathrm{ppm}\right)$.

Figures 9 and 10 show the $\mathrm{CO}$ and $\mathrm{HC}$ conversion efficiency as a function of the substrate wall temperature for points \#A and \#P respectively. In order to capture with accuracy the light-off curve, the inlet gas temperature varies from $100^{\circ} \mathrm{C}$ to $500^{\circ} \mathrm{C}$ with a ramp of $1{ }^{\circ} \mathrm{C} / \mathrm{min}$. The mass flow impact is similar in $\mathrm{CO}$ and $\mathrm{HC}$. The $\mathrm{CO}$ conversion 
efficiency shows a clear shift to higher temperature in both points, although it is not compromising the ability to reach full conversion efficiency for this species if the temperature is high enough. On this concern, it is interesting to note the different location of the light-off as a function of the operating points, which is not only due to the different mass flow but also dependent on the gas composition as forward discussed. $T 50_{\mathrm{CO}}$ increases from $181^{\circ} \mathrm{C}$ to $198.5^{\circ} \mathrm{C}$ in point \#A. However, it is initially located at $155.5^{\circ} \mathrm{C}$ in point \#P, which would have its CO light-off at $172^{\circ} \mathrm{C}$ for the multi-cylinder engine conditions. These results are in agreement with those discussed in Section 4.2, i.e. to increase the mass flow gives as a result the light-off temperature increase. Despite the increase of the mass transfer coefficient caused by the mass flow increase, as shown in Figure 11 for low reactivity HC, its benefit is not enough to make up for the residence time reduction. This limits the effective bulk mass transfer and increases the light-off temperature more than $15^{\circ} \mathrm{C}$. The pore diffusion is not putting influence on this process because it is not dependent on the mass flow but on the Thiele number according to Eqs. (19)-(22). Despite the well-known effect of the mass flow, the comparison between points \#A and \#P reveals that the point \#A light-off is located at higher temperature although its mass flow is lower than in point \#P. The reason lies in the $\mathrm{CO}$ and THC mass fractions for these operating points. According to the definition of the inhibition term, the high raw $\mathrm{CO}$ mass fraction in point \#A inhibits $\mathrm{CO}$ and $\mathrm{HC}$ oxidation at low temperature much more than the high raw THC mass fraction in point \#P. This is clearly observed in Figure 12, which represents the oxidation inhibition term for these points. The difference is several orders of magnitude below $250{ }^{\circ} \mathrm{C}$.

The THC conversion efficiency is also affected by changes in mass flow for specific pollutant mass fractions and by raw CO mass fraction difference between specific operating points. As shown in plots (b) of Figures 9 and 10, the increase in mass flow penalises the light-off temperature, whose increase ranges from $5{ }^{\circ} \mathrm{C}$ to $20^{\circ} \mathrm{C}$. At a more detailed level, taking into account a bi-modal $\mathrm{HC}$ chemical kinetics by distinguishing between high and low reactivity $\mathrm{HC}$, the THC conversion efficiency shows an increase in $T 50_{T H C}$ from $240^{\circ} \mathrm{C}$ to $245.5^{\circ} \mathrm{C}$ for point \#A and from $212.5^{\circ} \mathrm{C}$ to $232.5^{\circ} \mathrm{C}$ for point \#P. Despite the lower $T 50_{T H C}$ in point \#P because of its lower raw CO mass fraction, the penalty in light-off temperature is greater in this point than in point \#A. This is due to the combination of high mass flow and raw THC mass fraction in point \#P, which damages the HC bulk mass transfer. As a consequence, the maximum THC conversion efficiency is limited to $93 \%$ at $300^{\circ} \mathrm{C}$, as represented in Figure 10(b).

To isolate the influence of the raw emission mass fraction, the performance of the DOC against RCCI and CDC emission boundaries is compared in Figure 13 for point \#P. The most restrictive multi-cylinder engine case has been considered in this study. CDC emissions in point \#P were $224 \mathrm{ppm}$ in $\mathrm{CO}$ and $111 \mathrm{ppm}$ in THC mass fraction. According to these boundaries, point \#P shows a clear decrease in CO and THC light-off temperature under CDC operation, as observed in Figure 13(a) and (b) respectively. $T 50_{C O}$ decreases from $172^{\circ} \mathrm{C}$ for RCCI combustion to $115^{\circ} \mathrm{C}$ when the engine operates with $\mathrm{CDC}$, i.e. $57^{\circ} \mathrm{C}$ in light-off temperature reduction. With respect to $\mathrm{THC}, T 50_{T H C}$ moves from $232.5^{\circ} \mathrm{C}$ to $190^{\circ} \mathrm{C}$ but high reactivity $\mathrm{HC}$ even shows almost full abatement at $100^{\circ} \mathrm{C}$.

The deterioration of the DOC performance when it operates under RCCI boundary conditions must be found in the inhibition effect of high CO and THC mass fraction. The oxidation inhibition term suffers a huge increase when RCCI combustion is applied to point \#P. This is shown in Figure 14, which compares the oxidation inhibition term of 


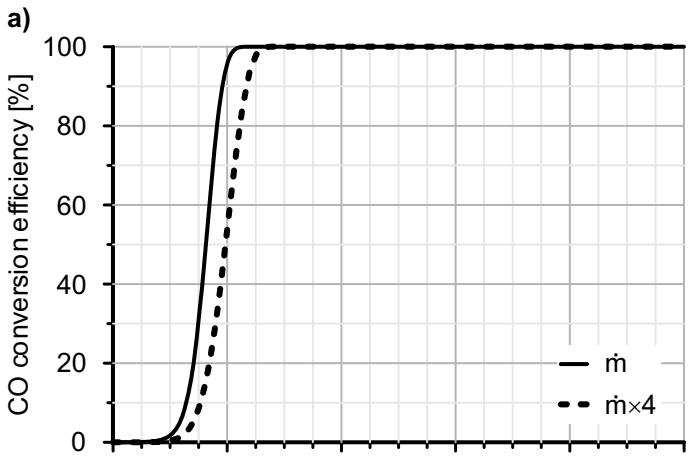

b)

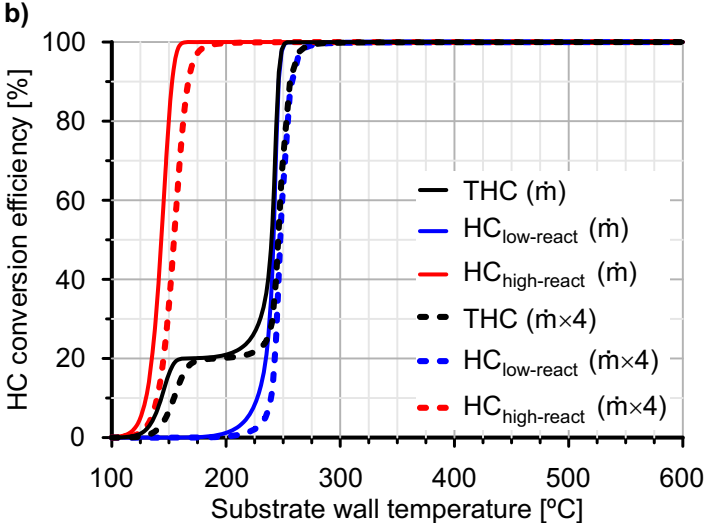

Figure 9: $\mathrm{CO}$ and $\mathrm{HC}$ conversion efficiency in point $\mathrm{\# A}$ as a function of the substrate temperature for single-and multi-cylinder engine mass flow conditions.

point \#P under CDC conditions against the one obtained under RCCI combustion. The difference is more than three orders of magnitude in the light-off temperature range, although the difference decreases as the temperature increases. In addition, it is relevant to highlight that this difference would increase with CO mass fraction, as previously shown in the comparison between points \#A and \#P under RCCI conditions in Figure 12.

The convergence between both inhibition terms is reached around $250^{\circ} \mathrm{C}$. It explains the lack of relevant differences in conversion efficiency at high temperature. The lower THC conversion efficiency in CDC case at high temperature is only explained by a lower reaction rate caused by the lower THC mass fraction. Once at this point, to resort to the internal pore diffusion efficiency, which is represented in Figure 15 for $\mathrm{CO}$ and HC, makes sense. The results reveal that this mechanism has a second order impact on the DOC efficiency when moving from CDC to RCCI conditions. CDC case, i.e. low CO and THC mass fraction, leads the internal pore diffusion efficiency to lower values than under RCCI operation. This fashion is especially noticeable for $\mathrm{CO}$ and high reactivity $\mathrm{HC}$ at low temperature, so that falls into the light-off region. The CDC internal pore diffusion efficiency for $\mathrm{CO}$ and high reactivity $\mathrm{HC}$ is shifted around $50^{\circ} \mathrm{C}$ towards low temperature with respect to the RCCI case. By contrast, this effect is observed at medium temperature for low reactivity HC. These results indicate that this limitation of the CDC case has lower 

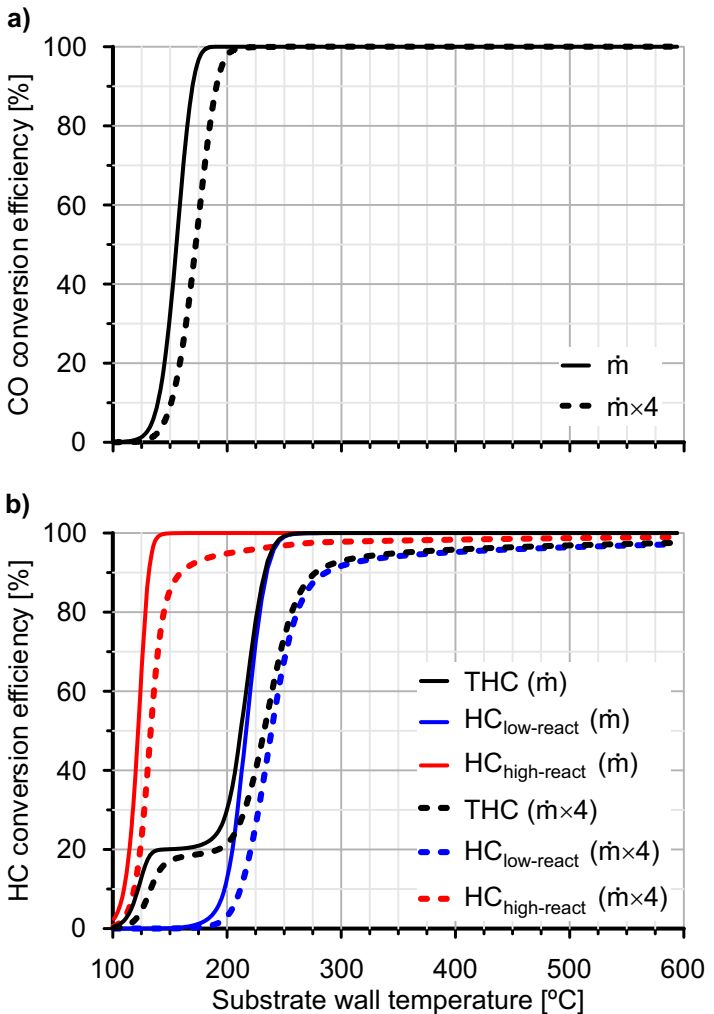

Figure 10: $\mathrm{CO}$ and $\mathrm{HC}$ conversion efficiency in point $\mathrm{\# P}$ as a function of the substrate temperature for single-and multi-cylinder engine mass flow conditions.

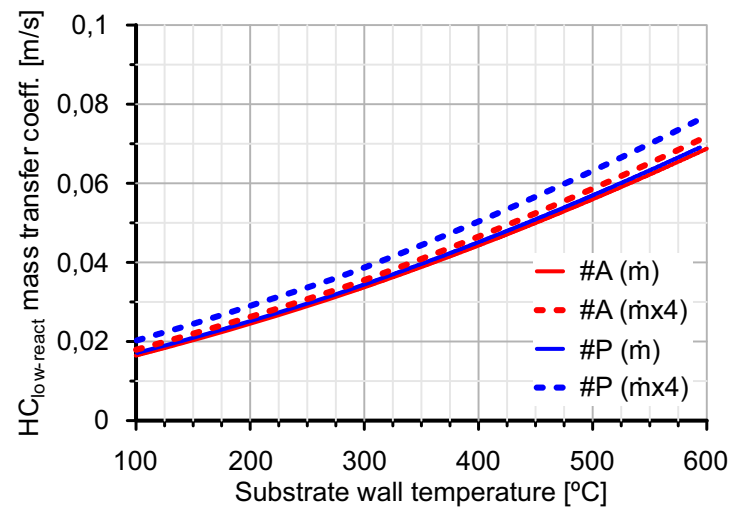

Figure 11: Mass transfer coefficient of low reactivity HC in points \#A and \#P as a function of the substrate temperature for single-and multi-cylinder engine mass flow conditions.

impact than the increase in the oxidation inhibition term brought by the high pollutant mass fraction that characterises the RCCI combustion. Nevertheless, it contributes to the lower conversion efficiency shown by the CDC case at high temperature, when RCCI and CDC inhibition terms converge. 


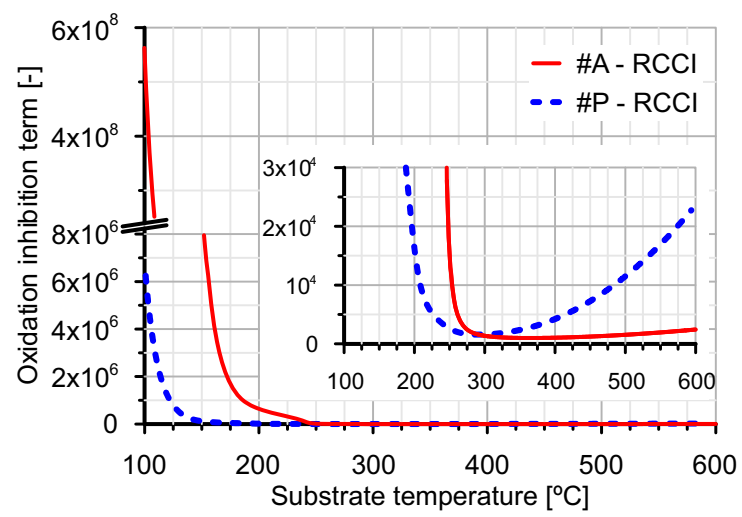

Figure 12: Oxidation inhibition term of points \#A and \#P under RCCI operation.

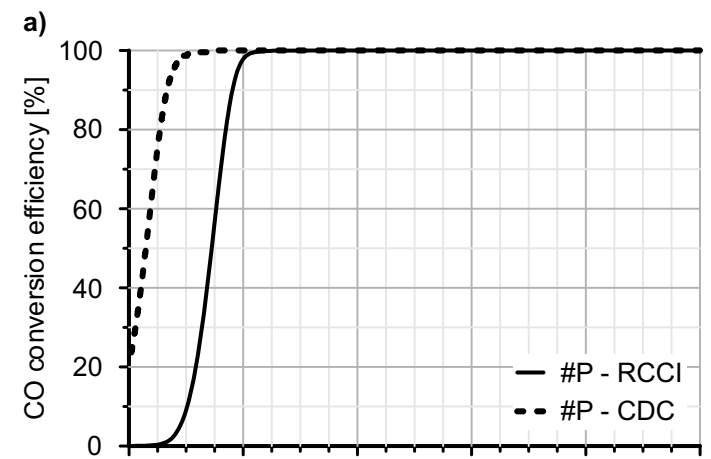

b)

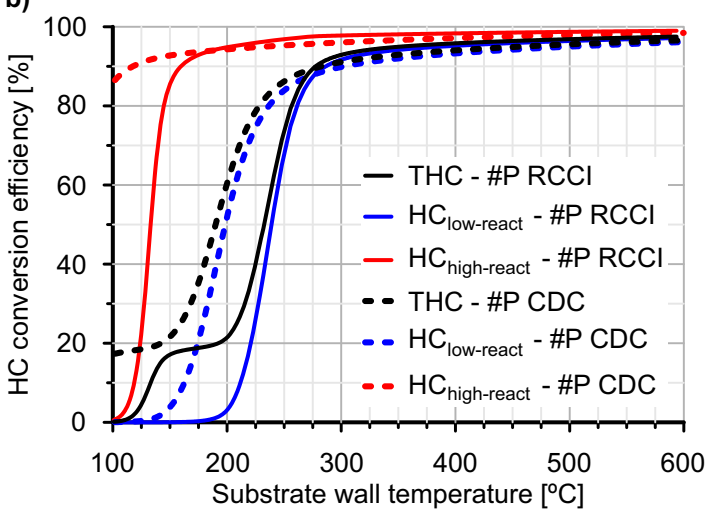

Figure 13: $\mathrm{CO}$ and $\mathrm{HC}$ conversion efficiency in $\mathrm{RCCI}$ and $\mathrm{CDC}$ point \#P as a function of the substrate temperature for multi-cylinder engine mass flow conditions.

\section{Conclusions}

The response of a conventional DOC has been investigated in this work in order to get better understanding on the capability of CDC catalysts to meet $\mathrm{CO}$ and THC abatement requirements operating under RCCI combustion condi- 


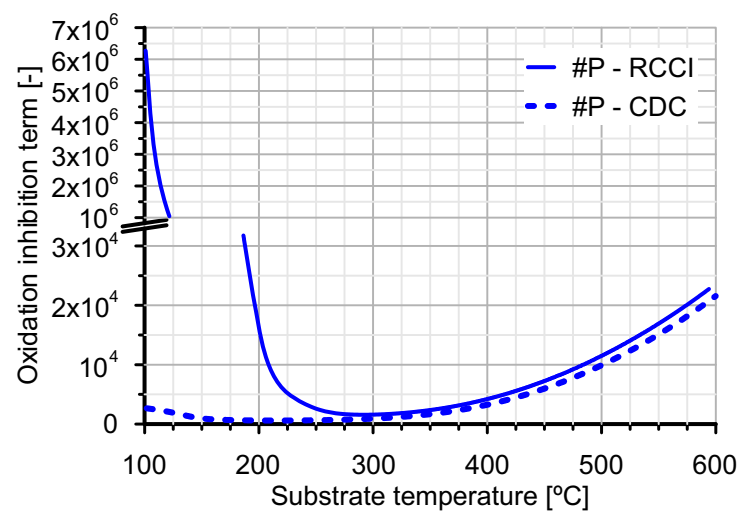

Figure 14: Oxidation inhibition term of point \#P under RCCI and CDC operation.

a)

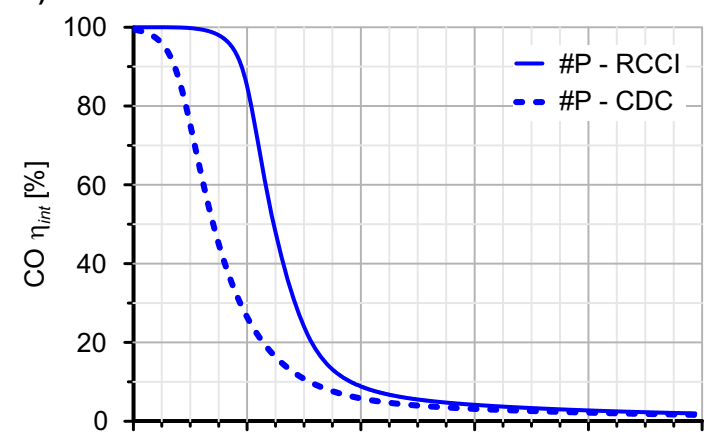

b)

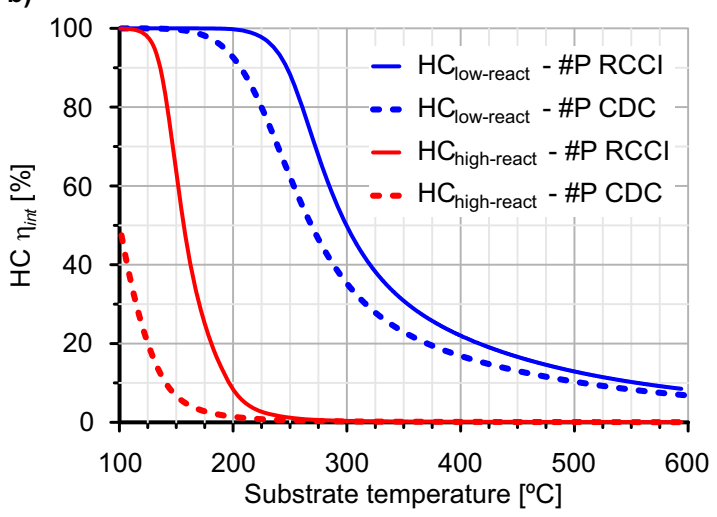

Figure 15: $\mathrm{CO}$ and $\mathrm{HC}$ internal pore diffusion efficiency of point \#P under RCCI and CDC operation.

tions. The experiments have been conducted in single-cylinder engine tested under steady-state operation. The test matrix has provided raw $\mathrm{CO}$ and THC emissions representative of RCCI combustion in a wide range of exhaust mass flow and gas temperature, which covers the light-off region for both pollutants. Next, the tests have been modelled 
using a lumped DOC model that accounts for the influence of the pollutants concentration, the internal pore diffusion and the bulk mass transfer on the effective reaction rate of $\mathrm{CO}$ and $\mathrm{HC}$ oxidation as well as $\mathrm{HC}$ adsorption/desorption.

The model has shown good ability to capture the conversion efficiency of the pollutant species by applying a calibration methodology combining an $\mathrm{HC}$ adsorption test and steady-state operating conditions tested in a row from low to high temperature and mass flow. In addition, the effect of multi-cylinder engine conditions has been explored by increasing the exhaust mass flow in every tested point while keeping constant the remainder parameters, in particular the gas temperature and the $\mathrm{CO}$ and THC mass fraction. These extended operating conditions have evidenced the importance of the residence time in the DOC performance because of the very high raw $\mathrm{CO}$ and THC mass fraction typical from the RCCI combustion. A clear decrease in conversion efficiency has been found at very low temperature. In fact, the THC conversion efficiency has shown a decrease in the whole temperature range mainly. It is mainly because of the low reactivity of a large part of the HC species, which leads to a maximum conversion efficiency around $95 \%$. At low temperature, the adsorption and the oxidation of high reactivity $\mathrm{HC}$ are also penalised as the mass flow increases, moving the maximum conversion efficiency in this range to $25 \%$. The damage in adsorption is especially important, since the limited storage capacity of the zeolite coating is added as a challenge to handle the high RCCI THC emission during warm-up operation.

A series of light-off simulations by sweeping the inlet gas temperature have been performed in order to analyse the response of the full-size DOC to $\mathrm{CO}$ and $\mathrm{HC}$ oxidation in controlled conditions. When comparing RCCI operating points, which are all characterised by high $\mathrm{CO}$ mass fraction in the exhaust gas, operating points with higher $\mathrm{CO}$ emission give as a result higher light-off temperature. Once established the boundaries of a particular operating point, the sensitivity of its light-off temperature to the residence time has been shown to be dependent on the baseline mass flow and the raw THC emissions. The CO light-off temperature increased more than $15^{\circ} \mathrm{C}$ for $\mathrm{CO}$ when moving from single to multi-cylinder mass flow. However, the THC light-off temperature variation is more sensitive to the operating point, i.e. mass flow and raw THC concentration, with an increase ranging between $5{ }^{\circ} \mathrm{C}$ and $20^{\circ} \mathrm{C}$. In fact, the maximum THC conversion efficiency is even decreased towards $95 \%$ due to bulk mass transfer limitations when THC concentration is very high. However, the most interesting outcome is the sensitivity of the light-off temperature to the $\mathrm{CO}$ inhibition.

The penalty due to oxidation inhibition brought by the high $\mathrm{CO}$ and THC concentration of the RCCI combustion has been evidenced comparing against an equivalent CDC case. The lower CO and THC emission of CDC leads to low value of the inhibition term in the light-off range. Consequently, the CO and THC conversion efficiency highly improves at low temperature. In fact, the $\mathrm{CO}$ and $\mathrm{THC}$ light-off temperature is shown to decrease around $50{ }^{\circ} \mathrm{C}$ in $\mathrm{CDC}$ in comparison to RCCI conditions for the analysed operating point considered in this work. The comparison of the DOC response under CDC and RCCI boundaries has also revealed that the different pollutants concentration involves a variation in the internal pore diffusion. Its efficiency evolution is shifted towards the low temperature range in $\mathrm{CDC}$ around $50^{\circ} \mathrm{C}$ for $\mathrm{CO}$ and high reactivity $\mathrm{HC}$ and $30^{\circ} \mathrm{C}$ for low reactivity $\mathrm{HC}$. However, the earlier decrease in internal pore diffusion efficiency as the temperature increases is a second order effect in comparison to other terms. 
In fact, the inhibition between species, which varies more than 3 orders of magnitude when comparing high and low pollutant concentration, i.e. RCCI against CDC, governs the performance in the low temperature region. The DOC is benefited by the lower emissions of the CDC despite it also leads to lower internal pore diffusion efficiency.

The combination of experimental and theoretical results has shown that the increased raw $\mathrm{CO}$ and THC emissions related to RCCI combustion affect the DOC sizing requirements. As a rule of thumb, an optimum performance at low operating temperature requires an increase in the nominal CDC DOC size. This would increase the adsorption capability in absolute terms and would reduce the light-off temperature by improving the bulk mass transfer to inhibition trade-off via residence time increase.

\section{Acknowledgements}

This research has been partially supported by FEDER and the Government of Spain through project TRA201679185-R. Additionally, the Ph.D. student María José Ruiz has been funded by a grant from Universitat Politècnica de València with reference number FPI-2018-S2-10.

\section{References}

[1] Araghi Y, Kroesen M, Van Wee B. Identifying reasons for historic car ownership and use and policy implications: An explorative latent class analysis. Transport Policy 2017;56:12-18.

[2] Luján JM, Bermúdez V, Dolz V, Monsalve-Serrano J. An assessment of the real-world driving gaseous emissions from a Euro 6 light-duty diesel vehicle using a portable emissions measurement system (PEMS). Atmos Environ 2018;174:112-121.

[3] Johnson T, Joshi A. Review of vehicle engine efficiency and emissions. SAE Technical Paper 2018-01-0329; 2018. https://doi.org/10.4271/2018-01-0329.

[4] González J, Otsuka Y, Araki M, Shiga S. Impact of new vehicle market composition on the light-duty vehicle fleet CO2 emissions and cost. Energy Procedia 2017;105:3862-3867.

[5] Singh P, Thalagavara AM, Naber J, Johnson JH, Bagley ST. An experimental study of active regeneration of an advanced catalyzed particulate filter by diesel fuel injection upstream of an oxidation catalyst. SAE Technical Paper 2006-01-0879; 2006. https://doi.org/10.4271/2006-010879 .

[6] Nova I, Tronconi E. Urea-SCR technology for deNOx after treatment of diesel exhausts. Springer; 2014. ISBN 978-1-4899-8071-7.

[7] Serrano JR, Climent H, Piqueras P, Angiolini E. Filtration modelling in wall-flow particulate filters of low soot penetration thickness. Energy 2016;112:883-898.

[8] Lújan JM, Bermúdez V, Piqueras P, García-Afonso Ó. Experimental assessment of pre-turbo aftertreatment configurations in a single stage turbocharged Diesel engine. Part 1: Steady-state operation. Energy 2015;80:599-613.

[9] García-Valladolid P, Tunestal P, Monsalve-Serrano J, García A, Hyvönen J. Impact of diesel pilot distribution on the ignition process of a dual fuel medium speed marine engine. Energy Convers Manage 2017;149:192-205.

[10] Ynagihara H, Sato Y, Mizuta J. A simultaneous reduction in NOx and soot in diesel engines under a new combustion system (Uniform Bulky Combustion System - UNIBUS). 17th International Vienna Motor Symposium; 1996.

[11] Koci CP, Ra Y, Krieger R, Andrie M, Foster DE, Siewert RM, Durrett RP, Ekoto I, Miles PC. Detailed unburned hydrocarbon investigations in a highly-dilute diesel low temperature combustion regime. SAE International Journal of Engines 2009;2:858-879.

[12] Kusaka J, Okamoto T, Daisho Y, Kihara R, Saito T. Combustion and exhaust gas emission characteristics of a diesel engine dual-fueled with natural gas. JSAE Review 2000;21:489-496. 
[13] Kokjohn SL, Hanson RM, Splitter DA, Reitz RD. Fuel reactivity controlled compression ignition (RCCI): a pathway to controlled highefficiency clean combustion. Int J Engine Res 2011;12:209-226.

[14] Inagaki K, Fuyuto T, Nishikawa K, Nakakita K, Sakata I. Dual-fuel PCI combustion controlled by in-cylinder stratification of ignitability. SAE Technical Paper 2006-01-0028; 2006. https://doi.org/10.4271/2006-01-0028.

[15] Benajes J, Molina S, García A, Monsalve-Serrano J. Effects of low reactivity fuel characteristics and blending ratio on low load RCCI (reactivity controlled compression ignition) performance and emissions in a heavy-duty diesel engine. Energy 2015;90:1261-1271.

[16] Li Y, Jia M, Yachao C, Xie M, Reitz R. Towards a comprehensive understanding of the influence of fuel properties on the combustion characteristics of a RCCI (reactivity controlled compression ignition) engine. Energy 2016;99:69-82.

[17] Benajes J, Molina S, García A, Monsalve-Serrano J. Effects of direct injection timing and blending ratio on RCCI combustion with different low reactivity fuels. Energy Convers Manage 2015;99:193-209.

[18] Yang Y, Dec JE, Dronniou N, Sjöberg M. Tailoring HCCI heat-release rates with partial fuel stratification: Comparison of two-stage and single-stage-ignition fuels. P Combust Inst 2011;33:3047-3055.

[19] Curran SJ, Hanson RM, Wagner RM. Reactivity controlled compression ignition combustion on a multi-cylinder light-duty diesel engine. Int J Engine Res 2012;13:216-225.

[20] Benajes J, García A, Monsalve-Serrano J, Boronat V. Gaseous emissions and particle size distribution of dual-mode dual-fuel diesel-gasoline concept from low to full load. Appl Therm Eng 2017;120:138-149.

[21] Benajes J, García A, Monsalve-Serrano J, Boronat V. Achieving clean and efficient engine operation up to full load by combining optimized RCCI and dual-fuel diesel-gasoline combustion strategies. Energy Convers Manage 2017;136:142-151.

[22] García A, Monsalve-Serrano J, Roso VR, Martins MES. Evaluating the emissions and performance of two dual-mode RCCI combustion strategies under the World Harmonized Vehicle Cycle (WHVC). Energy Convers Manage 2017;149:263-274.

[23] Carlsson P, Skoglundh M. Low-temperature oxidation of carbon monoxide and methane over alumina and ceria supported platinum catalysts. Appl Catal B-Environ 2011;101:669-675.

[24] Mallamo F, Longhi S, Millo F, Rolando L. Modeling of diesel oxidation catalysts for calibration and control purpose. Int J Engine Res 2014;15:965-979.

[25] Prikhodko VY, Curran SJ, Parks JE, Wagner RM. Effectiveness of Diesel Oxidation Catalyst in Reducing HC and CO Emissions from Reactivity Controlled Compression Ignition. SAE Int. J. Fuels Lubr 2013;6:329-335.

[26] Westermann A, Azambre B, Finqueneisel G, Da Costa P, Can F. Evolution of unburnt hydrocarbons under "cold-start" conditions from adsorption/desorption to conversion: On the screening of zeolitic materials. Appl Catal B: Environ 2014;158-159: 48-59.

[27] Storey JME, Curran SJ, Lewis SA, Barone TL, Dempsey AB, Moses-DeBusk M, Hanson RM, Prikhodko VY, Northrop WF. Evolution and current understanding of physicochemical characterization of particulate matter from reactivity controlled compression ignition combustion on a multicylinder light-duty engine. Int J Engine Res 2016;18:505-519.

[28] Wurzenberger JC, Auzinger G, Heinzle R, Wanker R. 1D modelling of reactive fluid dynamics, cold start behavior of exhaust systems. SAE Technical Paper 2006-01-1544; 2006, https://doi.org/10.4271/2006-01-1544.

[29] Joshi SY, Harold MP, Balakotaiah V. Low-dimensional models for real time simulations of catalytic monoliths. AIChE J 2009;55(7):17711783.

[30] Wenzel S, Despujols B, Wahiduzzaman S, Papadimitriou I. Development of real time catalyst model for engine and powertrain control design, SAE Technical Paper 2009-01-1273; 2009, https://doi.org/10.4271/2009-01-1273.

[31] Guardiola C, Pla B, Piqueras P, Mora J, Lefebvre D. Model-based passive and active diagnostics strategies for diesel oxidation catalysts. Appl Therm Eng 2017;110:962-971.

[32] Payri F, Arnau FJ, Piqueras P, Ruiz MJ. Lumped approach for flow-through and wall-flow monolithic reactors modelling for real-time automotive applications. SAE Technical Paper 2018-01-0954; 2018. https://doi.org/10.4271/2018-01-0954.

[33] Olmeda P, Martín J, García A, Villalta D, Warey A, Doménech V. A combination of swirl ratio and injection strategy to increase engine efficiency. SAE International Journal of Engines 2017;10:1204-1216. 


\section{Nomenclature}

\section{Acronyms}

ATDC

ATS

CAD

CDC

CI

CR

DI

DOC Diesel Oxidation Catalyst

DPF Diesel Particulate Filter

EGR Exhaust Gas Recirculation

GF Gasoline Fraction

HRF High Reactivity Fuel

LRF Low Reactivity Fuel

LTC Low Temperature Combustion

MON Motor Octane Number

MPRR Maximum Pressure Rise Rate 
PFI

Port Fuel Injection

PRR Pressure Rise Rate

RCCI Reactivity Controlled Compression Ignition

RON Research Octane Number

SCR

Selective Catalytic Reduction

THC Total Hydrocarbons

ULSD Ultra Low Sulfur Diesel

UTG Unleaded Test Gasoline

\section{Latin letters}

A

Area $\left[\mathrm{m}^{2}\right]$

$c_{p}$

Specific heat $[\mathrm{J} / \mathrm{kgK}]$

C

Equivalent Thermal Capacity [J/K]

$d_{p, w c}$

Pore diameter of the catalyst washcoat $[\mathrm{m}]$

D

Diameter [m]

533

$D_{e f}$

Effective diffusivity $\left[\mathrm{m}^{2} / \mathrm{s}\right]$

$D_{K n} \quad$ Knudsen diffusivity $\left[\mathrm{m}^{2} / \mathrm{s}\right]$

$D_{m}$

Molecular diffusivity $\left[\mathrm{m}^{2} / \mathrm{s}\right]$

$E_{a} \quad$ Activation Energy [J/mol]

$G_{o x} \quad$ Inhibition term for oxidation reactions [-]

$H_{f} \quad$ Enthalpy of formation [J/mol]

$k_{m} \quad$ Mass transfer coefficient [m/s]

$k_{r} \quad$ Kinetic constant in reaction $r[1 / \mathrm{s}]$

$K_{i} \quad$ Inhibition term coefficient $i[1 / \mathrm{s}]$

$L \quad$ Length [m]

$\dot{m} \quad$ Mass flow $[\mathrm{m} / \mathrm{s}]$

$M \quad$ Molecular weight $[\mathrm{kg} / \mathrm{mol}]$

$\dot{n}_{\text {gas }} \quad$ Exhaust gas mole flow [mol/s]

$p \quad$ Pressure [Pa]

$P_{f} \quad$ Pre-exponential factor [1/s]

$\dot{q}_{h t} \quad$ Gas to wall heat exchange [W]

$\dot{q}_{r} \quad$ Reaction power [W]

$\dot{q}_{r}^{\prime \prime} \quad$ Reaction power per unit of volume $\left[\mathrm{W} / \mathrm{m}^{3}\right]$ 


\section{Greek letters}

534

\begin{tabular}{|c|c|}
\hline$\alpha$ & Channel width $[\mathrm{m}]$ \\
\hline$\Delta H_{\frac{a d s}{d e s}}$ & Adsorption-desorption enthalpy $[\mathrm{J} / \mathrm{mol}]$ \\
\hline$\varepsilon$ & Porosity $[-]$ \\
\hline$\zeta$ & Tortuosity $[-]$ \\
\hline$\eta_{\text {int }}$ & Internal pore diffusion efficiency [-] \\
\hline$\theta$ & Surface coverage $[-]$ \\
\hline$\kappa$ & Conductivity [W/mK] \\
\hline$v$ & Diffusion volume $\left[\mathrm{m}^{3} / \mathrm{mol}\right]$ \\
\hline$v$ & Stoichiometric coefficient $[-]$ \\
\hline$\rho$ & Density $\left[\mathrm{kg} / \mathrm{m}^{3}\right]$ \\
\hline$\tau$ & Residence time $[\mathrm{s}]$ \\
\hline$\varphi$ & Thiele modulus $[-]$ \\
\hline$\psi_{H C}$ & $\mathrm{HC}$ specific storage capacity $\left[\mathrm{mol} / \mathrm{m}^{3}\right]$ \\
\hline$\Psi_{H C}$ & HC storage capacity [mol] \\
\hline
\end{tabular}

Equivalent thermal resistance $[\mathrm{K} / \mathrm{W}]$

Reaction rate of species $n[1 / \mathrm{s}]$

Universal gas constant $[\mathrm{J} / \mathrm{molK}]$

Reynolds number [-]

Sherwood number [-]

Specific surface $\left[\mathrm{m}^{-1}\right]$

Time [s]

Temperature $\left[{ }^{\circ} \mathrm{C}\right]$

Velocity $[\mathrm{m} / \mathrm{s}]$

Volume $\left[\mathrm{m}^{3}\right]$

Thickness [m]

Molar fraction of species $n[-]$

Mass fraction of species $n[-]$

\section{Subscripts}

ads $\quad$ Adsorption 


$\begin{array}{ll}\text { ax } & \text { Axial } \\ c & \text { Conduction } \\ \text { can } & \text { Canning } \\ \text { cat } & \text { Catalyst } \\ \text { ch } & \text { Monolith channel } \\ \text { des } & \text { Desorption } \\ \text { ef } & \text { Effective } \\ \text { ext } & \text { External } \\ \text { gap } & \text { Gap between mat and canning } \\ \text { gas } & \text { Exhaut gas flow } \\ \text { in } & \text { Inlet } \\ \text { int } & \text { Internal } \\ \text { mat } & \text { Canning mat } \\ \text { mon } & \text { Monolith } \\ n & \text { Related to species } n \\ \text { out } & \text { Outlet } \\ \text { ox } & \text { Oxidation } \\ \text { post } & \text { Related to a device downstream of the monolith } \\ \text { pre } & \text { Related to a device upstream of the monolith } \\ r & \text { Reaction } \\ \text { rad } & \text { Radial } \\ \text { sur } & \text { Wurface } \\ \text { we } & \text { Wall } \\ & \end{array}$

\section{Superscripts}

$p$

Time-step identifier 